\title{
Uncertainty in temperature response of current consumption-based emissions estimates
}

\author{
J. Karstensen, G. P. Peters, and R. M. Andrew \\ Center for International Climate and Environmental Research - Oslo (CICERO), P.O. Box 1129, Blindern, \\ 0318 Oslo, Norway
}

Correspondence to: J. Karstensen (jonas.karstensen@ cicero.oslo.no)

Received: 17 July 2014 - Published in Earth Syst. Dynam. Discuss.: 9 September 2014

Revised: 8 April 2015 - Accepted: 13 April 2015 - Published: 27 May 2015

\begin{abstract}
Several studies have connected emissions of greenhouse gases to economic and trade data to quantify the causal chain from consumption to emissions and climate change. These studies usually combine data and models originating from different sources, making it difficult to estimate uncertainties along the entire causal chain. We estimate uncertainties in economic data, multi-pollutant emission statistics, and metric parameters, and use Monte Carlo analysis to quantify contributions to uncertainty and to determine how uncertainty propagates to estimates of global temperature change from regional and sectoral territorial- and consumption-based emissions for the year 2007. We find that the uncertainties are sensitive to the emission allocations, mix of pollutants included, the metric and its time horizon, and the level of aggregation of the results. Uncertainties in the final results are largely dominated by the climate sensitivity and the parameters associated with the warming effects of $\mathrm{CO}_{2}$. Based on our assumptions, which exclude correlations in the economic data, the uncertainty in the economic data appears to have a relatively small impact on uncertainty at the national level in comparison to emissions and metric uncertainty. Much higher uncertainties are found at the sectoral level. Our results suggest that consumption-based national emissions are not significantly more uncertain than the corresponding production-based emissions since the largest uncertainties are due to metric and emissions which affect both perspectives equally. The two perspectives exhibit different sectoral uncertainties, due to changes of pollutant compositions. We find global sectoral consumption uncertainties in the range of \pm 10 to $\pm 27 \%$ using the Global Temperature Potential with a 50-year time horizon, with metric uncertainties dominating. National-level uncertainties are similar in both perspectives due to the dominance of $\mathrm{CO}_{2}$ over other pollutants. The consumption emissions of the top 10 emitting regions have a broad uncertainty range of \pm 9 to $\pm 25 \%$, with metric and emission uncertainties contributing similarly. The absolute global temperature potential (AGTP) with a 50-year time horizon has much higher uncertainties, with considerable uncertainty overlap for regions and sectors, indicating that the ranking of countries is uncertain.
\end{abstract}

\section{Introduction}

Many studies have shown that national greenhouse gas (GHG) emission accounts can be viewed from either a production (territorial) or consumption perspective (Davis and Caldeira, 2010; Hertwich and Peters, 2009; Wiedmann, 2009; Peters and Hertwich, 2008). While the production view only looks at territorial emissions, the consumption view includes emissions from the production of imported products and excludes emissions from the production of exports. It has been shown that territorial emissions have decreased in most developed countries since 1990, but consumption-based emissions have increased (Peters et al., 2011c). This indicates that growth in consumption and international trade may undermine the effectiveness of climate policies that only limit emissions in a subset of countries, such as in the Kyoto Protocol (Wiebe et al., 2012; Kanemoto et al., 2013).

The concept of consumption-based emissions estimates can therefore be used to extend the cause-effect chain from consumption, to production, to emissions, and ultimately to 


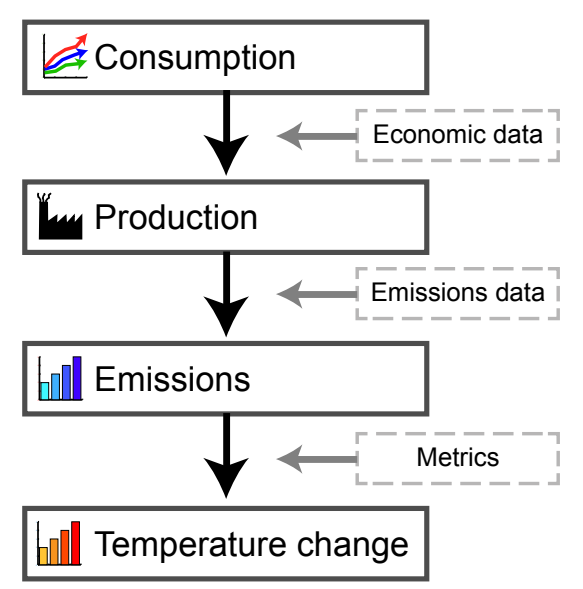

Figure 1. Flow chart of activities (bold boxes) and the data sets that determine transitions between them (dashed boxes).

global warming (Fig. 1). This is an important complement to the established territorial (Kyoto Protocol) viewpoint, particularly in that it links more directly to consumption as a key driver of emissions. More recent studies have broadened this concept to look at further consequences of increased global demand for traded products, such as deforestation (Karstensen et al., 2013), biodiversity loss (Lenzen et al., 2012b), dependency on traded fossil fuels (Andrew et al., 2013), land-use change (Weinzettel et al., 2013), and water footprints (Hoekstra and Mekonnen, 2012).

In the estimation of consumption-based emissions accounts, various data sets and models are combined in the calculations, and thus uncertainties and errors may arise in a number of data sets and models: emission data, metric data, economic data, etc. There are also uncertainties in assumptions and study design that can be more difficult to explicitly quantify, including which metric and time horizon to use for comparing pollutants, and how economic data for one specific year can be relevant to other years.

The uncertainty of many aspects of the cause-effect chain have been investigated previously (Höhne et al., 2010; Prather et al., 2012), but the link to consumption has not been made. There is a growing literature on the uncertainty in input-output (IO; economic) models used to estimate consumption-based emissions (Wilting, 2012; Lenzen et al., 2010; Peters et al., 2012; Moran and Wood, 2014; Inomata and Owen, 2014). Uncertainty in economic models, such as computable general equilibrium models, has also received attention recently (Elliott et al., 2012). However, the literature on uncertainty in economic data and models is still relatively small, and large knowledge gaps remain (IPCC, 2014).

A number of studies have investigated uncertainty in emissions (European Commission, 2011; UNEP, 2012; Marland et al., 2009; Macknick, 2011), both regionally and globally, but surprisingly there is still no emission data set with specified uncertainties at the country level across all climate- relevant species. In addition, there are almost no estimates of uncertainty at the sector level. Many aspects of uncertainty have been investigated in the climate system (Skeie et al., 2013; Prather et al., 2012; Myhre et al., 2013b), but there is little literature on the uncertainties in emissions metrics (Olivié and Peters, 2013; Shine et al., 2007; Reisinger et al., 2010). We are not aware of any studies that have estimated the uncertainty introduced by each model and data set (e.g., metric and IO uncertainties), or how uncertainty propagates when estimating climate change from consumption as a socioeconomic driver.

We extend the uncertainty analyses done by Prather et al. (2009), Höhne et al. (2010), and den Elzen et al. (2005) by including consumption-based emissions for a single year and using a temperature-based emission metric, which is arguably a more policy-relevant method of weighting emissions. We use Monte Carlo analysis and draw on previous studies of uncertainties to perturb and highlight the different contributors: economic data, emissions, and metric parameters, and then compare our results with the previous studies.

\section{Methods}

We consider the propagation of uncertainty from the point of consumption of goods and services (products), to the production of products where emissions occur, to the climate impacts caused by those emissions (Fig. 1). This can be thought of as a causal chain where consumption is assumed to be the primary driver, in turn driving production, which in turn leads to emissions, which then lead to temperature change. These components of the cause-effect chain are linked by calculation methodologies, each requiring parameterization, and we break the analysis into those three components: economic data, emission statistics, and emission metrics. We estimate the uncertainty for each of the components individually and finally connect the components to determine how uncertainty propagates through the cause-effect chain.

To determine the temperature response to a given level of consumption, we first map emission statistics for most important pollutants to producing regions and sectors (European Commission, 2011). Emissions are then converted into global temperature change using an emission metric (Aamaas et al., 2013). This means that we allocate future global temperature change to current production and consumption emissions. The allocation from producers to consumers (in sectors and regions) requires the global supply chain to be enumerated using economic production and trade data (Peters, 2008). Production often goes through several steps from extraction and refining to manufacturing and packaging, and finally to consuming markets. These linkages are represented in the global supply chain through monetary transactions. We normalize emissions using monetary output in each sector in each region, and allocate emissions according to consumer purchases. The result connects production and con- 
sumption, which are potentially geographically separated, and estimates the consumption that is driving current production emissions and hence future global temperature response.

All data sets and models introduce uncertainties in the analysis, and thus we estimate uncertainties in the economic data, the emissions data, and metric parameters in order to estimate uncertainties in the final results. We undertake the uncertainty analysis using Monte Carlo (MC) analysis, in which data sets and parameters are randomly perturbed according to predetermined distributions, and then sub-models are run sequentially to obtain distributions of the results (Granger Morgan et al., 1990). We isolate the individual contributions to uncertainty in the final results by perturbing individual components independently, before running everything together to estimate total uncertainty. The analysis considers parametric uncertainties for the components, as opposed to structural uncertainties, which would include the comparisons of different models and data sets (Peters et al., 2012). The next section lists the background data, and shows how uncertainties are estimated, before running the models and discussing the results.

\subsection{Data sets and models}

We use multi-regional input-output (MRIO) analysis to link economic activities from production to consumption, capturing global supply chains at the sectoral level (Davis and Caldeira, 2010; Wiedmann, 2009). We source our economic input-output data from the Global Trade Analysis Project (GTAP) database version 8, which comprises domestic and trade data for the entire world economy in 2007 divided into 129 regions and 58 sectors (Narayanan et al., 2012). We use these data to construct an MRIO model with the same regional and sectoral resolution, connecting all regions at the sector level (Andrew and Peters, 2013; Peters et al., 2011b). While GTAP does not provide uncertainty estimates for the economic data sets, it is possible to generate realistic uncertainty estimates for the GTAP database from proxy data. Since an MRIO database is an aggregation of multiple data sets, it inherits uncertainties from a number of sources, including source data, base year extrapolations, balancing and harmonization procedures, allocations, and aggregations (Wiedmann, 2009; Weber, 2008).

We use emissions data for the year 2007 from the Emissions Database for Global Atmospheric Research (EDGAR) for a number of pollutants (see Table 1), mapping these data to the regions and sectors of the GTAP database. Uncertainties in emission statistics for each pollutant are derived from multiple sources, e.g., for $\mathrm{CO}_{2}$ : the amount of fuel that is actually consumed, its carbon content, and how much of it is combusted. Additionally, to be consistent with top-down estimates, statistics are subject to adjustments and harmonization, and aggregated and grouped to economic sectors. Although national uncertainty may in some cases be large, global emissions are dominated by a small number of coun-

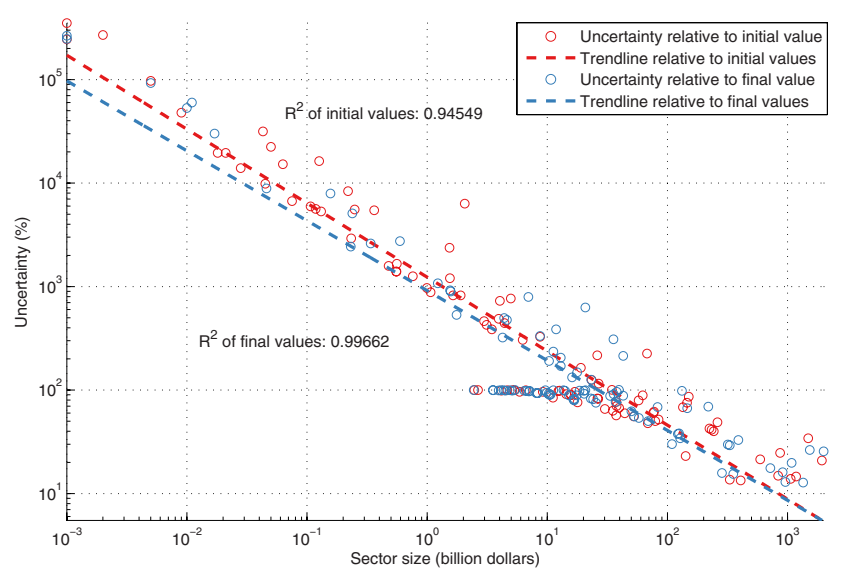

Figure 2. Error distribution of selected GTAP input-output data (taken from Table 19.6 in McDougall (2006) and shown as colored circles), and trend lines showing the fit of the general functional relationship explained by Eq. (1). Red and blue circles differ due to different methods of estimating the difference between unbalanced and balanced data. See the discussion in the text.

tries, and thus the global uncertainty is mostly a reflection of these countries' data quality (Andres et al., 2012).

The estimated global temperature impact of emissions are calculated using the global temperature change potential (GTP) metric (Aamaas et al., 2013; Shine et al., 2005), which is essentially a parameterization of more complex climate models. The metric uses pollutant characteristics (atmospheric lifetime, radiative forcing (RF)) as input, and unlike the more commonly used global warming potential (GWP) which only relates to RF, the GTP also includes estimates of climate temperature response (sensitivity) to changed RF in the atmosphere, which adds additional layers of uncertainties (Reisinger et al., 2010). We base our pollutant parameters on the ATTICA (European Assessment of Transport Impacts on Climate Change and Ozone Depletion) assessment (Fuglestvedt et al., 2010) and IPCC (2007, 212-213), and climate sensitivity and $\mathrm{CO}_{2}$ uncertainties on the latest CMIP5 data (Olivié and Peters, 2013). The uncertainties of the other pollutants are drawn from several sources, but mostly following the IPCC Fifth Assessment Report (Myhre et al., 2013a).

\subsection{General uncertainty relationships}

It has previously been shown that economic and emissions data show a general pattern where relative uncertainty is inversely related to the magnitude of the data point (Lenzen et al., 2010; Wiedmann, 2009; Wiedmann et al., 2008; Lenzen, 2000). The GTAP data used in our analysis follow a similar relationship, based on differences between the reported input data and the final data in the database after the harmonization and balancing of selected input-output (IO) data (Table 19.6 in McDougall, 2006). Figure 2 illustrates the inverse relationship between unbalanced and balanced data in the GTAP 
Table 1. Global emissions and uncertainties. The uncertainties indicate the 5-95\% (90\%) percentile range. PFCs include C2F6, C3F8, C4F10, C5F12, C6F14, C7F16, CF4, and c-C4F8. HFCs include HFC-125, HFC-134a, HFC-143a, HFC-152a, HFC-227ea, HFC-23, HFC236fa, HFC-245fa, HFC-32, HFC-365mfc, and HFC-43-10-mee, following UNEP (2012).

\begin{tabular}{lrrll}
\hline Pollutant & Global emissions (kt) & Uncertainty & Emissions references & Uncertainty references \\
\hline PFCs & $1.47 \times 10^{1}$ & $\pm 17 \%$ & European Commission (2011) & UNEP (2012) \\
$\mathrm{CH}_{4}$ & $3.25 \times 10^{5}$ & $\pm 21 \%$ & European Commission (2011) & UNEP (2012) \\
$\mathrm{CO}$ & $9.47 \times 10^{5}$ & $\pm 25 \%$ & European Commission (2011) & European Commission (2011) \\
$\mathrm{CO}_{2}$ & $3.14 \times 10^{7}$ & $\pm 8 \%$ & European Commission (2011) & UNEP (2012) \\
$\mathrm{HFCs}$ & $2.68 \times 10^{2}$ & $\pm 17 \%$ & European Commission (2011) & UNEP (2012) \\
$\mathrm{N}_{2} \mathrm{O}$ & $1.02 \times 10^{4}$ & $\pm 25 \%$ & European Commission (2011) & UNEP (2012) \\
$\mathrm{NF}_{3}$ & $1.58 \times 10^{-1}$ & $\pm 26 \%$ & European Commission (2011) & Weiss et al. (2008) \\
$\mathrm{NH}_{3}$ & $4.92 \times 10^{4}$ & $\pm 25 \%$ & European Commission (2011) & Clarisse et al. (2009) \\
$\mathrm{NMVOC}$ & $1.60 \times 10^{5}$ & $\pm 50 \%$ & European Commission (2011) & European Commission (2011) \\
$\mathrm{NO}_{x}$ & $1.27 \times 10^{5}$ & $\pm 25 \%$ & European Commission (2011) & European Commission (2011) \\
$\mathrm{SF}_{6}$ & $6.17 \times 10^{0}$ & $\pm 10 \%$ & European Commission (2011) & Levin et al. (2010) \\
$\mathrm{SO}_{2}$ & $1.22 \times 10^{5}$ & $\pm 11 \%$ & European Commission (2011) & Smith et al. (2010) \\
$\mathrm{BC}_{\mathrm{OC}}$ & $5.22 \times 10^{3}$ & $\pm 84 \%$ & Shindell et al. (2012) & Bond et al. (2004) \\
\hline
\end{tabular}

database together with a first-order regression $\left(R^{2}>0.9\right)$. These differences result from the GTAP harmonization and balancing process and values are only published for a sample of "large sectors in large regions with large relative changes" (McDougall, 2006). As a consequence of this data selection bias, it is not possible to convert these differences directly to more general sectoral uncertainties. Other uncertainty assessments in MRIO analysis have also taken this inverse relationship as the starting point (Lenzen et al., 2013; Moran and Wood, 2014; Lenzen et al., 2012a). Furthermore, a similar relationship is found with emissions data, based on a previous study of the UK Greenhouse Gas Inventory, where uncertainties were found using an error propagation model (Jackson et al., 2009). The underlying mechanisms for this inverse relationship are, however, unclear. The uncertainties may reflect conflicting data sources, unreliable measurements, bias in the source data, allocations and aggregations, base year extrapolations, estimates, and assumptions, etc. (Wiedmann, 2009; Weber, 2008; Lenzen, 2000), and it is unclear if all these uncertainties will lead to a clear inverse relationship with data values. It may be that the method of generating the data through some sort of optimization process leads to the relationship.

The data sets allow for the parameterization of a function mapping relative uncertainties to the magnitude of the data points. Following previous studies (Lenzen et al., 2010; Wiedmann et al., 2008), we assume the data follows a power function

$r_{x}=a x^{b}$

where $a$ and $b$ are coefficients. As there is very little data available to parameterize Eq. (1), we parameterize the relationship using two extreme data points (generally the uncer- tainty in the minimum and maximum values)

$$
\begin{aligned}
& a=\frac{r_{\min }}{v_{\max }^{b}}, \\
& b=\frac{r_{\max }-r_{\min }}{v_{\min }-v_{\max }} .
\end{aligned}
$$

It is generally argued that developed countries have lower uncertainty than developing countries due to the strength of institutions (Narayanan et al., 2012; Andres et al., 2012). The terms $r_{\min }$ and $r_{\max }$ define the smallest and largest relative errors, respectively, and are functions of developed and developing regions (using the Kyoto Protocol groupings of Annex $\mathrm{B}$ and non-Annex B countries). We assume that developing countries have double the uncertainties of developed countries, based on estimates for $\mathrm{CO}_{2}$ emissions (Andres et al., 2012; see further discussion in Sect. 2.4). This range is also sector and region dependent for the economic and emissions data, which we define below. The terms $v_{\min }$ and $v_{\max }$ refer to fixed minimum and maximum data values for sectors in a specific region given the uncertainty of $r_{\max }$ and $r_{\min }$, respectively. Figure 3 shows the functional relationship between sector sizes and uncertainties for economic and emissions data.

The lower threshold $v_{\min }$ is fixed for all regions in the economic and emissions data sets, giving sectors of the same size the same uncertainty, as the smallest sectors do not contribute much to the national totals. The upper threshold $v_{\max }$ can also be fixed to a certain sector size. However, uncertainties are likely to be regionally variable, as while a sector of, e.g., USD 1 billion might be very large for some countries, it might not be large in other regions. To account for this, we argue that the sectors' importance should vary with their contribution to the nations' totals, e.g., gross domestic product (GDP) or total emissions. We therefore scale $v_{\max }$ according 

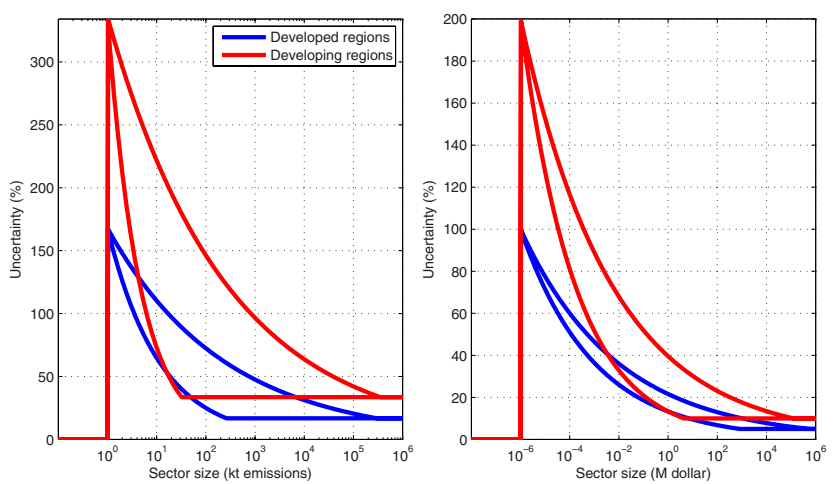

Figure 3. Functional relationship between sector sizes on the horizontal axes (in $\mathrm{kt}^{\mathrm{CO}_{2}}$ and million US dollars) and relative uncertainty on the vertical axes. The red lines outline the range of developing regions, while the blue lines show the range of developed countries. Each region has been estimated using a single unique curve, and all sectors, depending on their size, will fall on this curve. The form of this relationship is established independently for each pollutant.

to the regions' GDP and total emissions, for the respective data sets, so that the sectors' importance in different regions is reflected by their uncertainties. Sectoral values larger than $v_{\max }$ are given the same uncertainty as values equal to $v_{\max }$, to ensure that single large sectors do not affect the uncertainty in other large sectors (see details below).

To help illustrate the effects of the methodology, we show two examples: (1) one of China's largest economic sectors is the public administration, defense, education, and health sector, worth nearly USD 340 billion in 2007. Large sectors are given small uncertainties, and this sector is a substantial part of China's GDP (around 10\%). The uncertainty is therefore assumed to be one of the lowest in the country, but scaled up relative to other countries since China is not an Annex-B country. (2) One of the USA's smallest direct $\mathrm{CO}_{2}$-emitting sectors is the production of electronic equipment. Emitting roughly $1 \mathrm{Mt} \mathrm{CO}_{2}$, this is on the lower-end of the scale, contributing little to the national total of nearly $5000 \mathrm{Mt} \mathrm{CO}_{2}$. This sector is therefore given higher relative uncertainty. We expand on these examples with specific numbers in the next sections, after we define the uncertainty ranges for the economic and emissions data.

The estimated uncertainties are used to create distributions of perturbations. We impose lognormal distributions so that distributions with small relative spreads closely resemble normal distributions, while distributions with large relative spreads are skewed but avoid negative values (Fig. 4). The distributions are characterized using reported data as medians, and the spreads are (in order of decreasing preference) taken directly from the literature, derived from published analyses, or estimated. We define uncertainties as the 5-95\% confidence interval (90\% CI; equivalent to 1.64 standard deviations of a normal distribution).

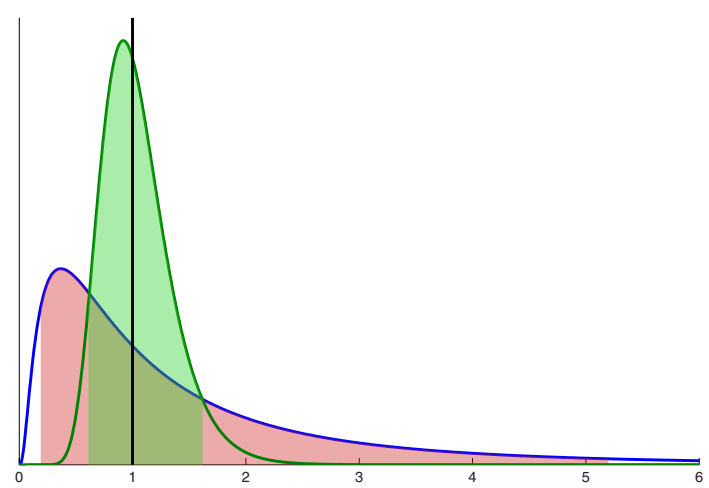

Figure 4. Distributions depending on median values and uncertainty. Both distributions have a median of 1 , while the near-normal distribution (green) has a relative uncertainty of $100 \%$, the skew distribution has a relative uncertainty of $500 \%$. The green and red shaded areas indicate the 5-95\% (90\%) confidence intervals.

By randomly perturbing each data point, we assume no correlation in the uncertainties of economic and emissions data, which might not be accurate for some sector combinations (Peters et al., 2012). Implementing correlations in such an analysis is a major difficulty due to the size of the system under investigation and the lack of uncertainty data, but this may also have significant effects on the results. We discuss this further in Sect. 4. We do, however, undertake a simple sensitivity analysis on the parameter choices by comparing the final results on MRIO uncertainty with uncertainty from the GTAP table showing extreme observations.

Aggregations of the results (from sectors to regions and from regions to the globe) usually decrease the relative uncertainty, so that the national uncertainty is lower than individual sectors, and global uncertainty is in some cases lower than national uncertainty. This is a result of the summation effect, and the relationship between sector sizes and uncertainties. The largest sectors are given the lowest uncertainties, so that the national uncertainty is largely a reflection of the uncertainty of the largest sectors. As an example of the summation effect, the relative uncertainty $r$ of adding $M \pm S$, $n$ times, is

$r=\frac{S / M}{\sqrt{n}}$,

assuming no correlations. To illustrate this effect, we show the uncertainty results at multiple levels.

\subsection{Economic data (multi-regional input-output model)}

The total sectoral output $\boldsymbol{x}$ of a region's economy (a vector) is the sum of intermediate consumption Ax and final consumption, $\boldsymbol{y}$ (Miller and Blair, 1985):

$\boldsymbol{x}=\mathbf{A x}+\boldsymbol{y}$,

where $\mathbf{A}$ is the inter-industry requirements matrix, which is equivalent to the technology used in each sector's production. 
We solve for the total output

$\boldsymbol{x}=(\mathbf{I}-\mathbf{A})^{-1} \boldsymbol{y}$,

where $(\mathbf{I}-\mathbf{A})^{-1}$ is the Leontief inverse $\mathbf{L}$. Emissions are estimated for a given $\boldsymbol{y}$ by first estimating the output, and then linking to sectoral emission intensities, $\boldsymbol{F}$. This gives the direct and indirect emissions (supply chain) emissions

$\boldsymbol{f}=\boldsymbol{F} \mathbf{L} \boldsymbol{y}$.

The economic data from GTAP is represented in a multiregional input-output (MRIO) model, which is constructed from a number of smaller data sets. The GTAP data set itself is based on a large number of smaller data sets (such as national IO tables and trade data from the UN's COMTRADE database), which are harmonized to remove inconsistencies (Andrew and Peters, 2013; Peters et al., 2011b; Narayanan et al., 2012). The construction of an MRIO table from the GTAP data is explained in detail elsewhere (Peters et al., $2011 \mathrm{~b}$ ). In the MC analysis, we perturb the components of the GTAP database (e.g., domestic IO data and international trade data) and not the resulting MRIO. In other words, we estimate the uncertainty of the MRIO data based on the uncertainty in the data used to construct it (Peters et al., 2011b), which consists of all data points in the GTAP database used to construct the MRIO model. This ensures that the uncertainties of the final model reflect the underlying uncertainties of the various input data. We construct the perturbed $\mathbf{L}$ and $\boldsymbol{y}$, before allocating the direct emissions $\boldsymbol{F}$ (which are also perturbed) to consuming regions and sectors.

We calibrate the uncertainty relationship (Eq. 1) for the GTAP data using several data sets. From the trend lines created from the GTAP table (Fig. 2), we find the smallest uncertainty of the largest sectors to be at approximately $5 \%$. We therefore let $90 \%$ of perturbed values fall within $5 \%$ of the median, and set $r_{\min }=5 \%$ for the largest sectors (where $v_{\max }$ applies).

The upper threshold $v_{\max }$ is defined by the regions' GDP so that a sector of a specific size will have a larger importance (and hence a lower uncertainty) in a small region than in a large region. We use the UK data provided by Lenzen et al. (2010) to explain the range of uncertainties in a single economy. In this data set the largest sectors have the smallest error, and following the trend line we find that the largest value is about $4 \%$ of UK GDP. We use this to define the upper threshold $v_{\max }=4 \% \times \mathrm{GDP}_{r}$, which means that sectors at or above this value will be given the lowest national uncertainty $\left(r_{\min }\right)$. Figure 3 shows the result of the implementations, where the lines indicate the range of developing and developed regions' sector sizes and uncertainties.

For the smallest sectors we set $v_{\min }$ equal to USD 1 and assume $r_{\max }=100 \%$ (following Wiedmann et al., 2008), due to the lack of more precise regional uncertainty data. The USD 1 relates to a small value often used in the GTAP database (Peters, 2006). These parameters may seem somewhat arbitrary, but these choices are not overly important.
A value of USD 1 in an input-output table (IOT) is exceedingly small (it represents the economic relationship between two sectors over 1 year). Indeed, analysis shows that removing small values has a negligible effect on the estimates' consumption-based emissions (Peters and Andrew, 2012). Thus, USD 1 is effectively zero in our data set. It could also be argued that the value of USD 1 is highly uncertain and should have large uncertainty. Giving values smaller than this higher relative uncertainty causes highly skewed lognormal distributions for the perturbations (see Fig. 4). The GTAP data set has values as low as $7 \times 10^{-35}$ causing $r$ to be $6 \times 10^{6} \%$. Such highly skewed distributions for data points with small medians («USD 1) can lead to large imbalances in the table.

An IO model is balanced so that gross input equals gross output, a fundamental characteristic of input-output models (Leontief, 1970). The same applies for a multiregional model (MRIO). When perturbing the coefficients in an IO table, it ultimately upsets the balance. In principal, the IO table can be rebalanced, but given the size of the systems (about $7500 \times 7500$ matrices), rebalancing is prohibitively computationally expensive, and may reduce uncertainties as the perturbed values are changed. We therefore choose not to rebalance, which effectively causes the "unbalanced" component to be shifted to the value added. A concern is that the value added may become unrealistic (e.g., negative) as a consequence. The MC algorithm specifically outputs value added components to allow crosschecking imbalances with the raw data, and we find the distributions of the value added at the sector level to be within expected uncertainty bounds given the size of the value added. This is partially because of the parameterization of uncertainty we have used, and partially because the perturbations tend to cancel out (the sum of random numbers). Thus, we can justify not rebalancing our perturbed IOTs and assume the imbalances are allocated to the value added (without having a large effect on the value added). Implementing this general methodology has also led to relatively small regional uncertainties in other studies (Lenzen et al., 2010; Wiedmann et al., 2008). Structural uncertainties have also been found to be relatively small for major economies (Moran and Wood, 2014). As a simple sensitivity analysis of the input uncertainties, we also run the MC model with uncertainties according to the fit of the GTAP table uncertainties (trend line relative to final values, due to better fit; Fig. 2). This vastly increases the uncertainties of all sectors, and we do not constrain the upper or lower uncertainties, meaning that very small sectors will be given unrealistically large uncertainties (USD 1 gives $r=10^{9} \%$ ). This exercise is only valid for the data it represents, large sectors in large countries, but is useful for facilitating a discussion about uncertainties in economic data. We discuss these results when exploring MRIO uncertainties, but do not include this when combining uncertainties.

Expanding on our previous example of the Chinese public administration, defense, education, and health sector, we can 
now calculate the uncertainty. Each data point in our MRIO model consists of inputs from several different GTAP data sets. When these data sets are combined, together with the uncertainties, the MRIO model and its uncertainty are obtained. In the MC analysis, all data sets are given uncertainties and perturbations (according to the inverse relationship) before constructing the MRIO model. The Chinese public administration, defense, education, and health sector, which is a single sector in the final GTAP-MRIO model, is built up from several data sets (bilateral trade, intermediate demand, and final demand of households, governments, and capital investments). In our example, we choose to focus on one of the most significant contributors to this sector: domestic government consumption expenditure. This sub-data set has a sectoral range from $<1$ to USD 420 billion, which, when calculating the uncertainty, is constrained in the calculations by the lower and upper threshold $v_{\min }=\mathrm{USD} 1$ and $v_{\max }=4 \%$ of national GDP $=$ USD 130 billion. For the uncertainty, the general sectoral range is $r_{\min }=5 \%$ to $r_{\max }=100 \%$. GTAP estimates the value added in the sector in this sub-data set to be around USD 340 billion, which is $10 \%$ of national GDP. This is well above $v_{\max }$, giving this sector a relative uncertainty equal to $r_{\min }(5 \%)$. Since China is a non-Annex B country, this is doubled, leading to a final uncertainty of $10 \%$ for this sector in this sub-data set. The uncertainties for the other data points in the other sub-data sets that make up the Chinese public administration, defense, education, and health sector will be estimated similarly, and together explain the overall uncertainty of this sector in the GTAP-MRIO model.

\subsection{Emission statistics}

The pollutants considered are listed in Table 1, which cover anthropogenic emissions for the year 2007 which have an effect on the climate. We do not include emissions from short cycle biomass burning, as this is considered to have a short lifetime in the atmosphere due to regrowth. The data set originally includes $\mathrm{CO}_{2}$ emissions from forest fires and decay, which is a mix of natural and anthropogenic emissions. Extracting the anthropogenic emissions and mapping them to agricultural sectors would require crude assumptions. We therefore do not include emissions related to forest loss, but acknowledge that it would increase global $\mathrm{CO}_{2}$ emissions by roughly $12 \%$ (van der Werf et al., 2009). The EDGAR data set only provides crude information on uncertainty at the global level for some species (European Commission, 2011). Therefore, global and regional uncertainties in emissions are taken from a variety of sources (Table 1). Global fossil fuel $\mathrm{CO}_{2}$ emissions statistics are independently produced by several organizations, but they generally agree with each other within about $5 \%$ for developed countries and $10 \%$ for developing countries (Andres et al., 2012). The $\mathrm{CO}_{2}$ emission estimates are all based on energy data, and globally the emissions are thought to have an uncertainty of $\pm 10 \%$ using a
$95 \% \mathrm{CI}$ (UNEP, 2012). Global $\mathrm{SO}_{2}$ emissions have an estimated uncertainty of between \pm 8 and $\pm 14 \%$, while regional uncertainties may be as large as $\pm 30 \%$ (Smith et al., 2010). For $\mathrm{CH}_{4}, \mathrm{~N}_{2} \mathrm{O}$, and $\mathrm{F}$ gases, the uncertainty of global emissions have been estimated as $\pm 21, \pm 25$, and $\pm 17 \%$, respectively (UNEP, 2012).

Table 1 shows parameters and uncertainties for each pollutant used as median values in the perturbations. Very little data exist on the uncertainty of emissions by sector, especially on a pollutant and regional level. Lenzen et al. (2010) used a table of selected sectors of UK $\mathrm{CO}_{2}$ emissions to find uncertainties, originating from Jackson et al. (2009). According to the regression of the data points, within the limits of the data points, there is a spread of uncertainties by roughly a factor of 10 (Fig. 2 in Lenzen et al., 2010). We therefore estimate sectoral uncertainty using the same general relationship as with the economic data (Eq. 1), where the uncertainty of global emissions is used as a proxy for the lowest uncertainty estimate of the largest sectors $\left(r_{\min }\right)$ and the smallest sectors' uncertainty is scaled by 10 times $\left(r_{\max }=10 r_{\min }\right)$.

We assign developing countries an $r_{\min }$ and $r_{\max }$ which are double those of developed countries. We define $v_{\min }=1 \mathrm{kt}$ and $v_{\max }=5 \%$ of regional emissions. This dependence on total regional emissions shifts the function so that a sector of a specific size will have a larger importance (and hence a lower uncertainty) in a smaller region than in a larger region (Fig. 3). We do not distinguish between different sources of the same pollutant, due to a lack of information at the sector level. This is, in some cases, a crude simplification (e.g., when comparing uncertainties in emissions of certain pollutants from the agricultural sector and power generation). Similarly, for the emissions data, we set $v_{\min }$ equal to $1 \mathrm{kt}$ of emissions. Values below this (as with economic data) have little impact on the footprint of regions and sectors, and are therefore given zero uncertainty.

Expanding on our previous example of emissions from the USA's electronic equipment sector, we can now calculate the uncertainty. The USA's sectors have a range of $\mathrm{CO}_{2}$ emissions from $0.3 \mathrm{kt}$ to $2500 \mathrm{Mt}$, which is then constrained in the calculations by the lower and upper threshold $v_{\min }=1 \mathrm{kt} \mathrm{CO} 2$ and $v_{\max }=5 \%$ of national total $\mathrm{CO}_{2}=$ $247 \mathrm{Mt} \mathrm{CO}_{2}$. For $\mathrm{CO}_{2}$ uncertainty, the general sectoral range is from $r_{\min }=16 \%$ (or $\pm 8 \%$ ), taken from Table 1 , to $r_{\max }=$ $10 \times r_{\min }=160 \%$. The emissions in the electronic equipment sector are $1.2 \mathrm{Mt} \mathrm{CO}_{2}$, which is $0.02 \%$ of total emissions. This is in between $v_{\min }$ and $v_{\max }$, giving the $\mathrm{CO}_{2}$ emissions from this sector a relative uncertainty of $43 \%$. Since the USA is an Annex B country, this is not doubled.

With every sector data point having an uncertainty, we create perturbations which we can sum to get a bottom-up estimate of the national uncertainty. Table 2 shows several perturbations of sectors $\left(x_{i n}\right)$ for region $r$. Each perturbation $i$ leads to a new national total $\left(X_{i}\right)$. However, independent uncertainty estimates of national totals (e.g., national emissions) that may be available for some regions may conflict 
Table 2. Example of perturbations of sectors for a single region $r$, and the resulting distribution of the national total. This bottom-up uncertainty estimate may not be consistent with top-down uncertainty estimates.

\begin{tabular}{lcccccc}
\hline Region $r$ & Sector 1 & Sector 2 & Sector 3 & Sector $n$ & $\begin{array}{c}\text { National total } \\
\text { (sum of sectors) }\end{array}$ & $\begin{array}{c}\text { Distribution of } \\
\text { national totals }\end{array}$ \\
\hline Perturbation 1 & $x_{11}$ & $x_{12}$ & $x_{13}$ & $x_{1 n}$ & $X_{1}$ & \\
Perturbation 2 & $x_{21}$ & $x_{22}$ & $x_{23}$ & $x_{2 n}$ & $X_{2}$ & $\rightarrow X_{N}$ \\
Perturbation 3 & $x_{31}$ & $x_{32}$ & $x_{33}$ & $x_{3 n}$ & $X_{3}$ & \\
Perturbation $i$ & $x_{i 1}$ & $x_{i 2}$ & $x_{i 3}$ & $x_{i n}$ & $X_{i}$ & \\
\hline
\end{tabular}

with our bottom-up distributions of the national totals $\left(X_{N}\right)$. When summing the perturbed sectors $x_{i n}$ for a region, it is unlikely that the distribution of $\boldsymbol{X}_{N}$ will be the same as the known uncertainty in $X$.

Additionally, the uncertainty in $\boldsymbol{X}_{N}$ will depend on the number of elements contributing to the sum, according to standard propagation of uncertainty rules (RSS, root sum square; see earlier discussion on the summation effect). In practice, the uncertainty of $X$ may be based on several lines of evidence, which may even exclude sector-based data. To ensure that we can reproduce the top-down uncertainty estimates of $X$, we use constrained optimization (using a quadratic programming $(\mathrm{QP})$ methodology) to minimally adjust the perturbations of $x_{i n}$ to a given distribution of the $X_{N}$ (Table 2).

Given that we can adjust one iteration so that it sums to a fixed $X$, we then give $X$ a distribution based on known national uncertainties, and thus, each iteration of $X$ is used to balance the same iteration of the disaggregated sector data $\left(x_{i n}\right)$. This ensures that the sum of sectors $\left(X_{i}\right)$ always gives a $X_{N}$ with a known uncertainty. The cost of this adjustment is that the spread of the large values in each region (e.g., a large sector) are adjusted to fit the constraints. To meet the criteria of, e.g., a narrower distribution of the aggregated values, the large values have to be given a narrower distribution as well. This methodology allows us to give realistic uncertainties for each $x_{i n}$ leading to an $X_{N}$ with a known uncertainty. We do not perform such balancing on the MRIO input data (previous section) as it is too computationally expensive, and there is little top-down data on uncertainties in economic data.

\subsection{Emission metrics}

To link emissions to temperature change, we use the global temperature change potential (GTP) as a metric to compare and aggregate pollutants (Shine et al., 2007). This gives an estimate of the global-mean surface temperature change due to a pulse of emissions from a specific pollutant, and is a simple way of modeling the much more complex climate system and its response. Uncertainties in metric values can arise from a number of factors, including pollutant parameters (RF and lifetime) and the response of the climate system. Although it has been shown that the GTP may have larger relative uncertainties than the alternative metric global warm- ing potential (GWP) (Aamaas et al., 2013; Reisinger et al., 2010) and it has been criticized for some of its characteristics (Pierrehumbert, 2014), the GTP directly links to global temperature change and is thus arguably more policy relevant (Shine et al., 2005). In addition, the physical interpretation of the GWP is less clear and the metric has been criticized by many authors (Peters et al., 2011a; Shine, 2009; Pierrehumbert, 2014). The GTP metric is calculated using impulse response functions, which explain the interaction of pollutant $i$ in the atmosphere (impulse response function; $\mathrm{IRF}_{i}$ ) and the climate system (temperature) response to a pulse emission $\left(\mathrm{IRF}_{T}\right)$ with specific RF and atmospheric lifetime.

We briefly describe the metric equations here, and refer to existing literature for more details (Aamaas et al., 2013; Fuglestvedt et al., 2010; Olivié and Peters, 2013; Myhre et al., 2013b). The absolute GTP (AGTP) for each pollutant $i$ is defined as

$\operatorname{AGTP}_{i}(H)=\int_{0}^{H} \operatorname{RF}_{i}(t) \operatorname{IRF}_{T}(H-t) \mathrm{d} t$,

where the RF for a pulse emission is

$\mathrm{RF}_{i}(t)=\mathrm{RE} \times \mathrm{IRF}_{i}=A_{i} \exp \left(-\frac{t}{\tau_{i}}\right)$,

where $t$ is time (years), $H$ is the time horizon (years), $A_{i}$ is the radiative efficiency for pollutant $i\left(\mathrm{~W}\left(\mathrm{~m}^{-2} \mathrm{~kg}\right)\right)$, and $\tau_{i}$ is the decay time for pollutant $i$ (years). The AGTP metric is dependent on the IRF of temperature, which incorporates the climate system response in global-mean surface temperature to a given RF. The climate response is modeled using two decaying exponential functions representing (1) the relative fast response of the atmosphere, the land surface, and the ocean mixed layer, and (2) the relative slow response of the deep ocean (Peters et al., 2011a),

$\mathrm{IRF}_{T}=\sum_{j=1}^{J} \frac{c_{j}}{d_{j}} \exp \left(-\frac{t}{d_{j}}\right)$,

where $J$ is the number of decay terms (usually two), $c_{j}$ is a component of the climate sensitivity $\left.\left(\mathrm{K}_{(\mathrm{Wm}}^{-2}\right)\right)$, where the total climate sensitivity $\lambda=\sum c_{j}$, and $d_{j}$ is the decay 
Table 3. Metric parameters with uncertainties. Note that the uncertainties are derived from CMIP5 data and Joos et al. (2013), but we use the corresponding distributions listed in Table 5 and 6 in the study by Olivié and Peters (2013) to account for correlations.

\begin{tabular}{lrlr}
\hline Parameters & Values & Unit & Uncertainties \\
\hline Climate sensitivity $f_{1}$ & 0.43 & $\mathrm{~K} \mathrm{Wm}^{-2}$ & $\pm 29 \%$ \\
Climate sensitivity $f_{2}$ & 0.32 & & $\pm 59 \%$ \\
\hline Climate sensitivity decay $\tau_{1}$ & 2.57 & year & $\pm 46 \%$ \\
Climate sensitivity decay $\tau_{2}$ & 82.24 & & $\pm 192 \%$ \\
\hline $\mathrm{CO}_{2}$ weight $a_{0}$ & 0.23 & & $\pm 20 \%$ \\
$\mathrm{CO}_{2}$ weight $a_{1}$ & 0.28 & & $\pm 33 \%$ \\
$\mathrm{CO}_{2}$ weight $a_{2}$ & 0.35 & & $\pm 28 \%$ \\
$\mathrm{CO}_{2}$ weight $a_{3}$ & 0.14 & & $\pm 30 \%$ \\
\hline $\mathrm{CO}_{2}$ decay $\tau_{0}$ & Infinite & year & - \\
$\mathrm{CO}_{2}$ decay $\tau_{1}$ & 239.6 & & $\pm 58 \%$ \\
$\mathrm{CO}_{2}$ decay $\tau_{2}$ & 18.42 & & $\pm 68 \%$ \\
$\mathrm{CO}_{2}$ decay $\tau_{3}$ & 1.64 & & $\pm 63 \%$ \\
\hline
\end{tabular}

time (years) of component $c_{j}$. These two functions are explained by lifetime and climate sensitivity for the individual components (Table 3 ). The $\lambda$ explains the change in equilibrium global-mean temperature due to forcing by a pollutant in the atmosphere. We parameterize the IRF according to the results from CMIP5 covering 15 different climate models (Olivié and Peters, 2013). This data set is parameterized by relatively short climate runs (140-150 years), and thus it is more representative of the short-term climate response (less than 100 years) compared to the equilibrium response (see Olivié and Peters, 2013 for details). Nevertheless, the data set leads to a median $\lambda=0.75 \mathrm{~K} \mathrm{Wm}^{-2}$ (equivalent to $2.8^{\circ} \mathrm{C}$ global-mean temperature increase), which is consistent with the climate response (sensitivity) of a doubling of $\mathrm{CO}_{2}$ concentration in the atmosphere within the range of 1.5 to $4.5^{\circ} \mathrm{C}$ (IPCC, 2013).

As $\mathrm{CO}_{2}$ has a more complex interaction in the atmosphere and can not be sufficiently modeled with a single exponential decay, we define the RF for $\mathrm{CO}_{2}$ as a sum of exponentials (Aamaas et al., 2013):

$\mathrm{RF}_{\mathrm{CO}_{2}}(t)=A_{\mathrm{CO}_{2}}\left\{a_{0}+\sum_{i=1}^{I} a_{i}\left(1-\exp \left(-\frac{t}{\tau_{i}}\right)\right)\right\}$,

where $a_{i}$ is the weight of each exponential, which by definition has to sum to one $\left(\sum a_{i}=1\right)$, and $I$ is the number of exponentials. We follow Joos et al. (2013) and use four exponentials and weights, and randomize the multiple lifetimes and coefficients so that the coefficients always sum to 1 , following Olivié and Peters (2013). The use of four different timescales was found to be sufficient to model $\mathrm{CO}_{2}$ behavior in the atmosphere compared to advanced climate models (Olivié and Peters, 2013). Correlations between the parameters were implemented for $\mathrm{CO}_{2}$ and $\mathrm{IRF}_{T}$, also based on Olivié and Peters (2013), but the effect of the correlations on temperature results was found to be small (less than $1 \%$ of AGTP50 value for $\mathrm{CO}_{2}$ ).

Estimates from the literature are used as the median (Fuglestvedt et al., 2010) and estimates of uncertainty as spread of the distributions (Tables 4 and 5). For the non-reactive pollutants, we randomized the single RF and lifetime values, as these are represented by only a single decay function. The RF used in the calculations includes the indirect effects of chemical reactions from the ozone precursors $(\mathrm{CO}$, $\mathrm{NO}_{x}$, and NMVOC), which were perturbed similarly as the other pollutants. This accounts for three indirect forcing effects: formation of $\mathrm{O}_{3}$ (causing positive $\mathrm{RF}$ by $\mathrm{CO}, \mathrm{NO}_{x}$, and NMVOC), changing $\mathrm{CH}_{4}$ levels (causing positive $\mathrm{RF}$ by $\mathrm{CO}$ and $\mathrm{NMVOC}$, and negative $\mathrm{RF}$ by $\mathrm{NO}_{x}$ ), and $\mathrm{CH}_{4}$-induced $\mathrm{O}_{3}$ effects (causing positive $\mathrm{RF}$ from $\mathrm{CO}$ and NMVOC, and negative $\mathrm{RF}$ from $\mathrm{NO}_{x}$ ) (Aamaas et al., 2013). The indirect effect of $\mathrm{SO}_{2}$ is included by scaling the metric value, where the indirect effect of $\mathrm{SO}_{2}$ is estimated to be about $175 \%$ of the direct effect (Aamaas et al., 2013). This is a crude estimate, and while the indirect effect may be more uncertain than the direct effect, we use the same uncertainty for the direct and indirect effects due to lack of pollutant specific data (Boucher et al., 2013).

Our analysis of uncertainty contributions from emissions and metric parameters uses absolute GTP (AGTP) values with units of temperature change (in Kelvin or ${ }^{\circ} \mathrm{C}$ ). When later allocating temperature data in the economic model, we also use GTP values in units of $\mathrm{CO}_{2}$-equivalent (eq.) emissions for comparison. The GTP values are calculated by normalizing the AGTP values with reference to the AGTP values for $\mathrm{CO}_{2}$. When we connect the components for a full MC analysis, we choose a single time horizon for computational reasons. As discussed elsewhere (Fuglestvedt et al., 2010), choosing a time horizon includes value judgment, and is not based solely on a scientific judgment. We choose to focus on 
Table 4. $\mathrm{RF}$ values and uncertainties. Note that $\mathrm{CO}$, non-methane volatile organic compound (NMVOC) and $\mathrm{NO}_{x}$ are precursors, which have an effect on $\mathrm{O}_{3}$ and $\mathrm{CH}_{4}$ concentrations. Because of this, no single $\mathrm{RF}$ value can be given. The uncertainties indicate the 5-95\% (90\%) percentile range. Parameters from IPCC (2007, Table 2.14, p. 212-213).

\begin{tabular}{|c|c|c|c|c|}
\hline Pollutant & $\mathrm{RF}\left(\mathrm{Wm}^{-2} \mathrm{~kg}^{-1}\right)$ & Uncertainty & RF references & Uncertainty references \\
\hline PFCs & $6.40 \times 10^{-12}-1.06 \times 10^{-11}$ & $\pm 10 \%$ & IPCC (2007) & Myhre et al. (2013a) \\
\hline $\mathrm{CH}_{4}$ & $1.82 \times 10^{-13}$ & $\pm 17 \%$ & Fuglestvedt et al. (2010) & Myhre et al. (2013a) \\
\hline $\mathrm{CO}$ & - & $\pm 24 \%$ & Derwent et al. (2001) & Myhre et al. (2013a) \\
\hline $\mathrm{CO}_{2}$ & $1.81 \times 10^{-15}$ & $\pm 10 \%$ & Fuglestvedt et al. (2010) & Myhre et al. (2013a) \\
\hline HFCs & $6.74 \times 10^{-12}-1.53 \times 10^{-11}$ & $\pm 10 \%$ & Fuglestvedt et al. (2010), IPCC (2007) & Myhre et al. (2013a) \\
\hline $\mathrm{N}_{2} \mathrm{O}$ & $3.88 \times 10^{-13}$ & $\pm 17 \%$ & Fuglestvedt et al. (2010) & Myhre et al. (2013a) \\
\hline $\mathrm{NF}_{3}$ & $1.66 \times 10^{-11}$ & $\pm 10 \%$ & IPCC (2007) & Assumed \\
\hline $\mathrm{NH}_{3}$ & $-1.03 \times 10^{-10}$ & $\pm 123 \%$ & Shindell et al. (2009) & Myhre et al. (2013a) \\
\hline NMVOC & - & $\pm 41 \%$ & Collins et al. (2002) & Myhre et al. (2013a) \\
\hline $\mathrm{NO}_{x}$ & - & $\pm 120 \%$ & Wild et al. (2001) & Myhre et al. (2013a) \\
\hline $\mathrm{SF}_{6}$ & $2.00 \times 10^{-11}$ & $\pm 10 \%$ & Fuglestvedt et al. (2010) & Myhre et al. (2013a) \\
\hline Sulphate & $-3.20 \times 10^{-10}$ & $\pm 50 \%$ & Fuglestvedt et al. (2010) & Myhre et al. (2013a) \\
\hline $\mathrm{BC}$ & $1.96 \times 10^{-9}$ & $\pm 66 \%$ & Fuglestvedt et al. (2010) & Myhre et al. (2013a) \\
\hline $\mathrm{OC}$ & $-2.90 \times 10^{-10}$ & $\pm 68 \%$ & Fuglestvedt et al. (2010) & Myhre et al. (2013a) \\
\hline
\end{tabular}

Table 5. Lifetimes and uncertainties. Uncertainties for several gases' lifetimes are assumed, but a sensitivity analysis revealed that a change of this uncertainty will not have a large impact on the results (see metric results section below). Note that $\mathrm{CO}, \mathrm{NMVOC}$, and $\mathrm{NO}_{x}$ are precursors, which have an effect on $\mathrm{O}_{3}$ and $\mathrm{CH}_{4}$ concentrations. Because of this, no single lifetime can be given. Values and uncertainties for $\mathrm{CO}_{2}$ are given in Table 3. The uncertainties indicate the 5-95\% (90\%) percentile range. Parameters from IPCC (2007, Table 2.14, p. 212-213).

\begin{tabular}{lrrll}
\hline Pollutant & Lifetime (years) & Uncertainty & Lifetime references & Uncertainty references \\
\hline PFCs & $2600-50000$ & $\pm 20 \%$ & Fuglestvedt et al. (2010) & Assumed \\
$\mathrm{CH}_{4}$ & 12 & $\pm 19 \%$ & Fuglestvedt et al. (2010) & Myhre et al. (2013a) \\
$\mathrm{CO}$ & - & $\pm 20 \%$ & Fuglestvedt et al. (2010) & Assumed \\
$\mathrm{CO}_{2}$ & - & - & Fuglestvedt et al. (2010) & - \\
$\mathrm{HFCs}$ & $1.4-270$ & $\pm 12- \pm 29 \%$ & Fuglestvedt et al. (2010), & Myhre et al. (2013a), \\
& & & IPCC (2007) & Ko et al. (2013) \\
$\mathrm{N}_{2} \mathrm{O}$ & 114 & $\pm 13 \%$ & Fuglestvedt et al. (2010) & Myhre et al. (2013a) \\
$\mathrm{NF}_{3}$ & 740 & $\pm 13 \%$ & Fuglestvedt et al. (2010) & Ko et al. (2013) \\
$\mathrm{NH}_{3}$ & 0.02 & $\pm 20 \%$ & Fuglestvedt et al. (2010) & Assumed \\
$\mathrm{NMVOC}_{\mathrm{NO}}$ & - & $\pm 20 \%$ & Fuglestvedt et al. (2010) & Assumed \\
$\mathrm{SF}_{6}$ & - & $\pm 20 \%$ & Fuglestvedt et al. (2010) & Assumed \\
$\mathrm{Sulphate}_{\mathrm{BC}}$ & 3200 & $\pm 20 \%$ & Fuglestvedt et al. (2010) & Assumed \\
$\mathrm{OC}$ & 0.01 & $\pm 20 \%$ & Fuglestvedt et al. (2010) & Assumed \\
\hline
\end{tabular}

the impact at 50 years (AGTP50 and GTP50), as this is both consistent with current literature (Myhre et al., 2013b), and within reasonable time for when to expect global warming to exceed $2{ }^{\circ} \mathrm{C}$ (Joshi et al., 2011; Peters et al., 2013).

\section{Results}

Estimated uncertainties are used to create distributions of all data points. To analyze how various stages of the causeeffect chain contribute to overall uncertainty, we introduce uncertainty separately in each part of the chain before com- bining them all together (Fig. 1). We first show uncertainties resulting from (1) the economic data only, (2) the emissions data only, and (3) the metric calculations only. The final section, (4), connects these three parts together to follow uncertainty through the entire cause-effect chain. The results show uncertainty propagation from consumption to global temperature change. The analysis is based on $10000 \mathrm{MC}$ runs. 


\subsection{MRIO uncertainty}

In this section, we assume there are no uncertainties in the territorial emissions data or emission metrics, and thus the MRIO model uses unperturbed median estimates of GTP50 values for all pollutants when allocating emissions to consumers, and uncertainties are purely dependent on parametric uncertainty in the input data into the MRIO. In our analysis, each of the 129 countries has 57 producing sectors (not including households as they are considered final demand in the model, and therefore not included in the processing), and thus the MRIO table has 7353 rows and columns. We emphasize here, but discuss later, that we consider parametric uncertainties and not structural uncertainties.

Table 6 shows uncertainties in emissions embodied in imports and exports, as well as consumption, due to perturbations only on the economic data set. The exports indicate goods that are produced domestically but consumed abroad, while the imports indicate goods produced abroad but consumed domestically. The uncertainties in exported emissions are solely due to uncertainties in domestic economic data, thus reflecting the pattern of developed countries having higher uncertainties. Uncertainties in imported emission are generally higher than exported emissions, as the imports come from a number of different regions of which many may have high uncertainties (e.g., emerging and developing economies).

For the largest consumption paths, the consumption perspective is not substantially more uncertain than the corresponding territorial view due to economic uncertainties. Following the largest international fluxes embodied in trade from Davis and Caldeira (2010) aggregated over all sectors, we find $2 \%$ uncertainty in emissions embodied in products exported from China to the USA, $2 \%$ uncertainty from China to western Europe, $3 \%$ from China to Japan, and $1 \%$ from the USA to western Europe from economic uncertainties only. These fluxes are mainly dominated by the largest sectors, to which our method has assigned the smallest uncertainties. The export from China to the USA mainly originates in the manufacturing sectors, which combined is one of the largest Chinese sectors, therefore with relatively low uncertainties. Annex B countries are assigned lower uncertainties than non-Annex B countries, which explains the relatively low uncertainty from the USA to western Europe.

For smaller paths, there are much higher economic uncertainties. More than $20 \%$ of the international trade routes have a higher uncertainty than $10 \%$ (total number of trade routes is 128 regions $\times 128$ regions), while the median of all is $6 \%$ uncertainty. The uncertainties in consumption emissions for the top emitters are very low for two reasons: (1) the effect of summations and aggregations reduce the uncertainties on the national level (Eq. 4; much higher values are seen on a sectoral level), and (2) the distributions we give the perturbed data in the larger sectors are relatively small.
Since we start from the raw GTAP data to construct the MRIO table, and normalize and invert the MRIO table, a vast number of summations and multiplications are done with the initial perturbed data (an inversion in a single MC ensemble requires more than $10^{12}$ operations, which was estimated using the Lightspeed Matlab toolbox; Minka, 2014). Following RSS uncertainty propagation, the relative uncertainty will decrease when adding equally sized numbers with equally sized uncertainty (not an unrealistic assumption for inputoutput analysis). Thus, the relative uncertainty of the sum of a row in the MRIO (the output) will depend on the number, $n$, of large data points (Eq. 4). This problem can be avoided by using a quadratic programming approach to rebalance the sum to a given uncertainty (as we do for the emissions data), but we do not do this as (a) it is too computationally expensive, and (b) it would require balancing the entire MRIO table to get consistent sums. This problem is difficult to negotiate given the size of the database we are using, and consequently this exerts a downward pressure on MRIO uncertainties. Because of this, and because uncertainty ranges of input values are small for the largest and most important sectors, the final results have small uncertainties. A valid question is then how reliable the uncertainties are.

The "unfitted" and "fitted" data from Table 19.6 in the GTAP documentation (Fig. 2) act as a simple sensitivity analysis to our applied uncertainties; however, since this table only samples the very largest deviations, it is not representative of the uncertainties in the entire database. When we use these, we find that the uncertainties are much larger for the largest emitters (between 160 and $400 \%$ uncertainty for consumption-based emissions), and for small- and medium-sized countries the uncertainties becomes unrealistically large. Thus, the results are clearly sensitive to the input uncertainties. This is expected as the input uncertainties are outliers in the GTAP database, and thus the uncertainties are known to be large. As a consequence, the vastly perturbed values lead to ill-defined MRIO tables (outside of machine precision), which will compromise the accuracy of the final results (see discussion on skew distributions and small data points in the Methods section). However, as discussed earlier, using the difference between input and output values as a proxy of uncertainty is not straightforward. For example, the first data point in Table 19.6 indicates an input values of USD 2 billion and an output value of USD 132 billion, where the difference (relative to the initial value) can be interpreted as a change of $6500 \%$. This uncertainty is vast, and many data points have much larger differences. Because of these difficulties, and since the results are only valid for specific sectors, we do not show regional results from this analysis, but only use it for illustrative purposes.

Overall, we find small uncertainties in the MRIO results; however, the uncertainties in the end results are a function of the uncertainties in the input values, as shown by the sensitivity analysis. Furthermore, the input uncertainties are estimated from small amounts of data and many assumptions, 
Table 6. Uncertainties in allocated emissions due to uncertainties in the economic data set, by top 10 emitters. The territorial emissions are not perturbed, and thus they have no uncertainty.

\begin{tabular}{|c|c|c|c|c|c|c|c|c|c|}
\hline & & Region & Territorial & Exports & Uncertainty & Imports & Uncertainty & Consumption & Uncertainty \\
\hline \multirow{10}{*}{ 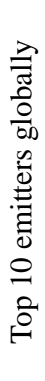 } & 1 & China & 7269 & 1966 & $1.7 \%$ & 400 & $2.1 \%$ & 5703 & $0.7 \%$ \\
\hline & 2 & United States of America & 6380 & 744 & $1.1 \%$ & 1411 & $1.2 \%$ & 7047 & $0.3 \%$ \\
\hline & 3 & Russian Federation & 2027 & 600 & $1.0 \%$ & 216 & $1.3 \%$ & 1642 & $0.5 \%$ \\
\hline & 4 & India & 1812 & 232 & $2.0 \%$ & 186 & $2.6 \%$ & 1766 & $0.5 \%$ \\
\hline & 5 & Japan & 1381 & 257 & $1.3 \%$ & 471 & $1.4 \%$ & 1595 & $0.5 \%$ \\
\hline & 6 & Germany & 957 & 324 & $0.9 \%$ & 498 & $1.0 \%$ & 1130 & $0.6 \%$ \\
\hline & 7 & Brazil & 750 & 127 & $2.1 \%$ & 116 & $3.1 \%$ & 739 & $0.7 \%$ \\
\hline & 8 & Canada & 626 & 194 & $1.0 \%$ & 209 & $1.5 \%$ & 641 & $0.7 \%$ \\
\hline & 9 & United Kingdom & 616 & 134 & $1.0 \%$ & 410 & $1.1 \%$ & 892 & $0.6 \%$ \\
\hline & 10 & Korea & 547 & 158 & $1.9 \%$ & 214 & $2.4 \%$ & 602 & $1.2 \%$ \\
\hline
\end{tabular}

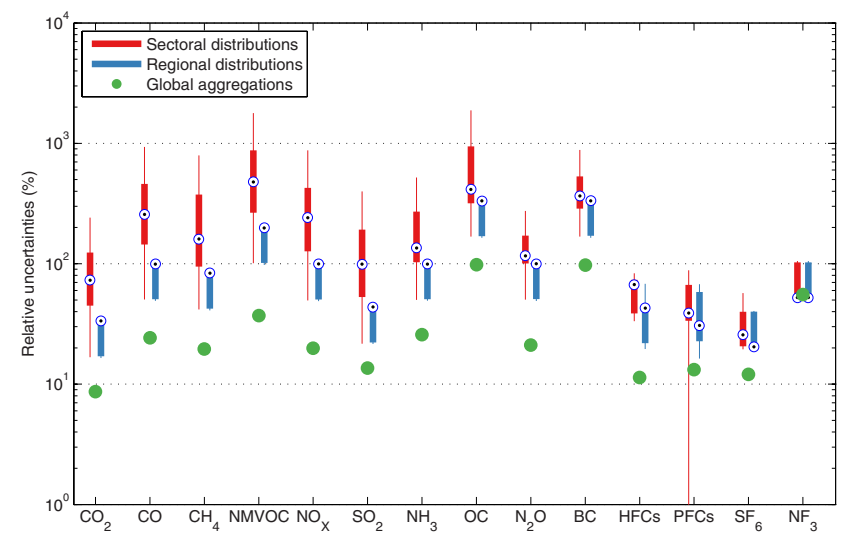

Figure 5. Relative uncertainties $(90 \% \mathrm{CI})$ in emissions of all pollutants for all sectors (red box plots), for national aggregates (blue box plots) and global aggregates (green dots). The edges of the boxes indicate the 25 th and 75 th percentiles, and the whiskers include extreme data points, but not outliers. The blue target symbols indicate the median value of the distributions. Pollutants are sorted according to global emissions in tons.

making the uncertainty estimates for the end results less robust. Although our results are supported by other studies that have performed parametric uncertainty analysis (Lenzen et al., 2010; Bullard and Sebald, 1988; Peters, 2007), structural uncertainties in MRIO analysis are found to be larger (Peters et al., 2012). Thus, we suggest that MRIO uncertainty may be best evaluated using a combination of structural uncertainties (model comparisons) and parametric Monte Carlo uncertainties.

\subsection{Emissions}

At the global level, uncertainties in emissions are known from previous studies (Table 1), which are used to estimate uncertainties of emissions occurring from production at the sectoral and regional level. Figure 5 shows the uncertainty of all data points (7482 sectors and 129 regions and global aggregations) for all pollutants. Each data point's uncertainty is dependent on the sector size, the region's GDP, and whether the region is a developed or developing country. Different activities are associated with different emissions, and thus not all sectors in all regions include emissions from all pollutants. Additionally, the perfluorinated chemical (PFC) and hydrofluorocarbon (HFC) groups are aggregates of several pollutants, and thus the spreads are based on different amounts of data.

The red box plots in Fig. 5 shows the sectoral distributions of the relative uncertainties, not including data points with zero uncertainties. Aggregations of sectors to individual countries (blue box plots) lower the uncertainty ranges, depending on the sectors' impact on national totals $\mathrm{NF}_{3}$ is a special case, where only one sector in each region has emissions, and thus sectoral and regional uncertainties are the same). The median values for the box plots indicate the skewness of the distributions. The distributions often have two distinct peaks (not visible in the box plots), which are developed and developing countries, where the latter group has higher uncertainty. The global aggregations are results of national totals, which are dominated by large regions (e.g., China and the USA). The bottom-up global uncertainties are not constrained by top-down estimates, as we are not using aggregated global emissions in the end results. They are, however, all (except $\mathrm{NF}_{3}$ due to few data points) lower than the input estimates from Table 1 due to the aggregation effect. Small regions with low emission and high uncertainties thus have little effect on the global uncertainties.

The well-mixed GHGs (WMGHGs; $\mathrm{CO}_{2}, \mathrm{CH}_{4}, \mathrm{~N}_{2} \mathrm{O}$, HFCs, PFCs, $\mathrm{SF}_{6}, \mathrm{NF}_{3}$ ) generally have lower emission uncertainties ( $9 \%$ uncertainty for the aggregated sum) than the short-lived pollutants (black carbon (BC), organic carbon (OC), $\mathrm{SO}_{2}, \mathrm{NH}_{3} ; 14 \%$ uncertainty) and precursors (CO, NMVOC, $\mathrm{NO}_{x} ; 19 \%$ uncertainty). The WMGHGs accounted for $39.4 \pm 1.5 \mathrm{Gt} \mathrm{CO}_{2}$-eq. emissions (using GTP50), while the short-lived pollutants accounted for $-4.6 \pm 0.6 \mathrm{Gt}$ $\mathrm{CO}_{2}$-eq. and the precursors accounted for $0.4 \pm 0.1 \mathrm{Gt} \mathrm{CO}_{2^{-}}$ eq. (where the two last groups have a mix of warming and 
cooling effects). Uncertainties in pollutant aggregates for emissions (in tons) and GTP50 ( $\mathrm{CO}_{2}$-eq.) values only include emission uncertainties, but are different due to the different weighting of pollutants and due to mixing of cooling and warming effects. Uncertainties of territorial emissions from developing countries (54\% of global emissions using GTP50) have a median value of $32 \%$, while developed regions have a median uncertainty of $16 \%$. These numbers are dominated by the uncertainty of $\mathrm{CO}_{2}$, and usually only small variations are seen due to other pollutants.

Globally, most emissions occur in the electricity generation (28\% of global emissions using GTP50) and manufacturing sectors $(25 \%)$ (see Supplement for sector aggregations). Uncertainties in emissions (in tons) from electricity range from $19 \%$ for $\mathrm{CO}_{2}$, to $27 \%$ for $\mathrm{SO}_{2}$ and to $60 \%$ for $\mathrm{NO}_{x}$, which are the most important pollutants (with the largest contributions to the sectoral GTP50 value). For energy-intensive manufacturing, $\mathrm{CO}_{2}$ (7\% uncertainty), $\mathrm{SO}_{2}$ $(8 \%)$, and $\mathrm{CH}_{4}(52 \%)$ are the most important pollutants. In the non-energy-intensive manufacturing sectors, $\mathrm{CO}_{2}(8 \%$ uncertainty), $\mathrm{SO}_{2}(16 \%)$, and HFCs $(21 \%)$ dominate.

For agriculture, $\mathrm{CH}_{4}\left(21 \%\right.$ uncertainty) and $\mathrm{N}_{2} \mathrm{O}(26 \%)$ are equally important to the GTP50 value, while $\mathrm{CO}(37 \%)$ comes third. $\mathrm{CH}_{4}$ has less uncertainty coming from agriculture than energy-intensive manufacturing, since for $\mathrm{CH}_{4}$ the agriculture sector is much larger, which is consistent with top-down estimates (Kirschke et al., 2013). The household sector emits mainly $\mathrm{CO}_{2}$ (8\% uncertainty), $\mathrm{BC}(156 \%)$ and OC $(140 \%)$ due to household fuels and private transportation. The transport sectors consists mainly of $\mathrm{CO}_{2}(5 \%)$, $\mathrm{SO}_{2}(9 \%)$, and $\mathrm{NO}_{x}(17 \%)$. Mining, services, and food sectors are small in a production view, and consist mainly of $\mathrm{CO}_{2}(4 \%), \mathrm{CH}_{4}(16 \%)$, and $\mathrm{SO}_{2}(9 \%)$. These estimates are aggregates of sectors and regions (and gases for HFCs and PFCs), and thus disaggregated data have larger uncertainties.

\subsection{Emission metrics}

Metric (temperature) values have an uncertainty range for the different pollutants and different time horizons, due to the perturbed metric parameters (RF, lifetime, and climate sensitivity). This includes uncertainties from mapping emissions to atmospheric concentrations through the global carbon cycle, which is represented by the relatively uncertain climate sensitivity. Figure 6 shows all pollutants on the same scale using AGTP for 2007 global emissions, with both relative and absolute uncertainties. The net temperature response (black dotted line) goes from negative to positive over the first few years, before the short-lived species decay, and the net effect becomes dominated by $\mathrm{CO}_{2}$ in the long run. The relative and absolute uncertainty of the net effect is largest in the first few years, and becomes roughly stable from 50 to 100 years. The strong temperature effects of short-lived climate forcers (SLCFs), and thus the high absolute uncertainties of the mix of pollutants increase the net uncertainty
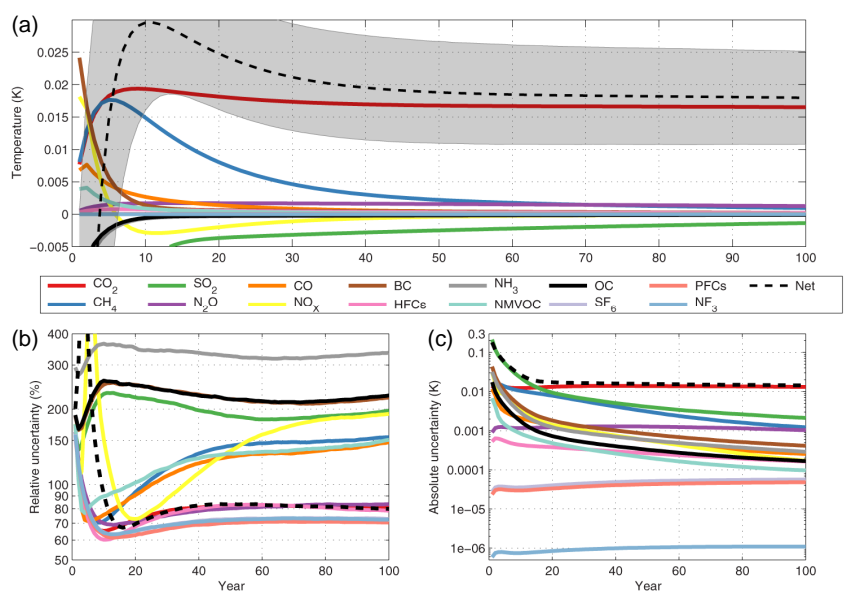

Figure 6. (a) The AGTP for a range of pollutants, with (b) relative and (c) absolute uncertainties due to metric parameters. Pollutants are sorted in the legend according to absolute temperature impact at 50 years. The shaded area around the net effect in subplot (a) indicates the $90 \%$ CI uncertainty. Subplot (b) is on the log scale, showing relative uncertainties. Subplot (c) (also using the log scale) shows the absolute uncertainty for a $90 \% \mathrm{CI}$, of which half is the upper shaded area in (a) and the other half is the lower shaded area.

in the first few years, but $\mathrm{CO}_{2}$ dominates the uncertainty after 20 years.

The top contributors to absolute uncertainties in the first year are $\mathrm{SO}_{2}, \mathrm{BC}$, and $\mathrm{NH}_{3} . \mathrm{BC}$ and $\mathrm{SO}_{2}$ have similar relative uncertainties, but since the emissions of $\mathrm{SO}_{2}$ are much larger, it has 5 times the absolute uncertainty. OC, BC, and $\mathrm{SO}_{2}$ have the largest uncertainties after approximately 10 years (except for $\mathrm{NH}_{3}$ due to its significantly larger $\mathrm{RF}$ uncertainty), as the uncertainties are dominated by RF and climate sensitivity uncertainties. $\mathrm{NO}_{x}$ has a very high relative uncertainty after 7 years because its temperature effect goes from positive to negative around this time.

Figure 7 shows a breakdown of the parameters contributing to relative uncertainty of the AGTP values by pollutant. MC runs with separate metric components were individually perturbed to isolate the individual contributions to uncertainties. For comparison, uncertainties in global emissions are also included in the graph, although not included when perturbing all components. Uncertainties in emissions and RF do not depend on the time horizon, and thus they are straight lines. However, as the precursors have combined effects (see methods) the uncertainty of RF on $\mathrm{CO}, \mathrm{NMVOC}$, and $\mathrm{NO}_{x}$ actually changes with time due to the different effects having different lifetimes.

For the first 3 years, the total uncertainty for most pollutants (except the SLCFs: $\mathrm{BC}, \mathrm{OC}, \mathrm{SO}_{2}$, and $\mathrm{NH}_{3}$ ) is completely dominated by the first decay parameter of the climate sensitivity, which has a median value of $2.6 \pm 1.2$ years (Olivié and Peters, 2013). For the WMGHGs, the parameter continues to dominate for approximately $6-8$ years, when the 

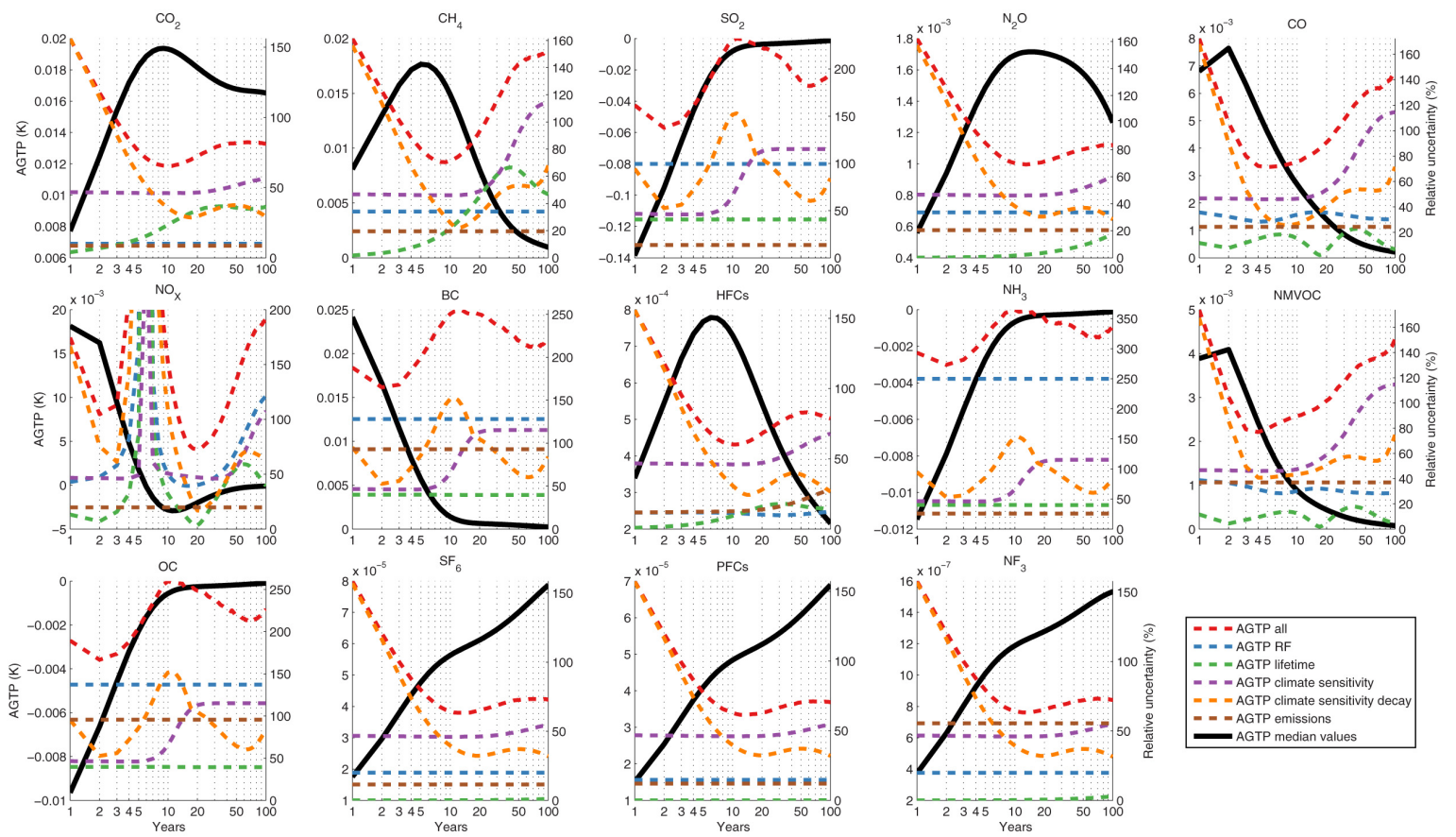

Figure 7. AGTP values (black lines) for all pollutants (sorted by absolute temperature impact at the 50-year time horizon) and relative uncertainties (dashed lines) for metric parameters, on the right vertical axis. AGTP median values use parameters from the literature, while AGTP values all show uncertainty with all parameters perturbed (excluding emissions). Uncertainties indicate the $90 \%$ CI range of the median values. Global emission uncertainties are derived from sector aggregations, and are the same as shown in Fig. 5.

uncertainty of the climate sensitivity component takes over and continues to dominate to at least 100 years. Between them they explain the largest contributions of uncertainties to the metric values for all time horizons. While the decay parameter explains the large uncertainties in the first years, the climate sensitivity parameter explains the increasing relative uncertainties towards 50 and 100 years. The climate sensitivity parameters are highly sensitive to the time horizon since they have different effects at different times. For $\mathrm{SO}_{2}$ and $\mathrm{NH}_{3}$, the first years are also effected by high uncertainties from RF. Other short-lived pollutants (BC and OC) have large contributions from both emissions and RF values.

At 50 years, $\mathrm{CO}_{2}$ and $\mathrm{CH}_{4}$ have additional significant contributions to uncertainties from lifetimes. Since they both have lifetimes within the ranges of the graph, they show variability depending on the time horizon. The shorter- and longer-lived pollutants show little variations in lifetime uncertainties over the different time horizons, as lifetimes are either too short or too long to have any effect within 100 years at this scale. The uncertainty of several gases' lifetimes are assumed (Table 5); however, the small impact from lifetime uncertainties in the metric values indicate that small changes of the median lifetimes will for most pollutants have very little effect. At 50 years, the short-lived pollutants have uncertainties ranging between \pm 95 and $\pm 165 \%$, while the WMGHGs have uncertainties ranging between \pm 35 and $\pm 70 \%$. The precursors have uncertainties around $\pm 65 \%$.
After 100 years, only the WMGHGs still have a significant temperature effect, which means that the SLCFs do not contribute with absolute uncertainties. In relative terms, shorter-lived pollutants have a rise in uncertainties from 50 to 100 years, while the opposite is true for the longer-lived pollutants. The last group is then completely dominated by climate sensitivity uncertainties. Most pollutants have relatively low uncertainty contributions from emissions as the global estimates are low, except for BC and OC. On a regional and sectoral level, the uncertainties from emissions are usually much more dominant, shifting the total uncertainties at all time horizons.

The literature consists of both studies which allocate emissions using the absolute metric (AGTP) and those that use the normalized metric (GTP). The GTP metric values are scaled with the AGTP values for $\mathrm{CO}_{2}$. When running the $\mathrm{MC}$ analysis, we create AGTP values for every iteration, which implies that $\mathrm{CO}_{2}$ always will be normalized by itself (by definition, $\mathrm{GTP}_{\mathrm{CO}_{2}}=1$ ). Therefore, the uncertainties of total emissions using GTP values are quite different to AGTP uncertainties since the dominant species $\left(\mathrm{CO}_{2}\right)$ has no metric uncertainty, and the uncertainties in other species are potentially amplified due to the uncertainty of $\mathrm{AGTP}_{\mathrm{CO}_{2}}$ values.

A second effect of using the GTP values is that the normalization of AGTP values include the climate sensitivity in both the numerator and denominator, which means that GTP values are less sensitive to climate sensitivity uncer- 
Table 7. Metric values uncertainties for the 20-, 50-, and 100-year time horizons. All metric parameters (excluding emissions) were perturbed. The uncertainties indicate the 5-95\% (90\%) percentile range, where the plus-minus notation is half of the $90 \%$ CI. Numbers are rounded to nearest $5 \%$, as multiple MC runs would give slightly different results (usually within 1-2\%).

\begin{tabular}{lrrrrrrrrr}
\hline Pollutants & AGTP20 & AGTP50 & AGTP100 & GTP20 & GTP50 & GTP100 & GWP20 & GWP50 & GWP100 \\
\hline PFCs & $\pm 30 \%$ & $\pm 35 \%$ & $\pm 35 \%$ & $\pm 20 \%$ & $\pm 20 \%$ & $\pm 20 \%$ & $\pm 15 \%$ & $\pm 15 \%$ & $\pm 15 \%$ \\
$\mathrm{CH}$ & $\pm 45 \%$ & $\pm 70 \%$ & $\pm 75 \%$ & $\pm 35 \%$ & $\pm 55 \%$ & $\pm 70 \%$ & $\pm 25 \%$ & $\pm 30 \%$ & $\pm 30 \%$ \\
$\mathrm{CO}$ & $\pm 45 \%$ & $\pm 65 \%$ & $\pm 75 \%$ & $\pm 35 \%$ & $\pm 45 \%$ & $\pm 65 \%$ & $\pm 20 \%$ & $\pm 20 \%$ & $\pm 25 \%$ \\
$\mathrm{CO}_{2}$ & $\pm 35 \%$ & $\pm 40 \%$ & $\pm 40 \%$ & $\pm 0 \%$ & $\pm 0 \%$ & $\pm 0 \%$ & $\pm 0 \%$ & $\pm 0 \%$ & $\pm 0 \%$ \\
$\mathrm{HFCs}$ & $\pm 30 \%$ & $\pm 40 \%$ & $\pm 40 \%$ & $\pm 20 \%$ & $\pm 20 \%$ & $\pm 20 \%$ & $\pm 15 \%$ & $\pm 15 \%$ & $\pm 20 \%$ \\
$\mathrm{~N}_{2} \mathrm{O}$ & $\pm 35 \%$ & $\pm 40 \%$ & $\pm 40 \%$ & $\pm 25 \%$ & $\pm 25 \%$ & $\pm 30 \%$ & $\pm 20 \%$ & $\pm 25 \%$ & $\pm 25 \%$ \\
$\mathrm{NF}_{3}$ & $\pm 35 \%$ & $\pm 35 \%$ & $\pm 35 \%$ & $\pm 20 \%$ & $\pm 25 \%$ & $\pm 25 \%$ & $\pm 15 \%$ & $\pm 20 \%$ & $\pm 20 \%$ \\
$\mathrm{NH}_{3}$ & $\pm 180 \%$ & $\pm 165 \%$ & $\pm 170 \%$ & $\pm 165 \%$ & $\pm 150 \%$ & $\pm 165 \%$ & $\pm 125 \%$ & $\pm 130 \%$ & $\pm 130 \%$ \\
$\mathrm{NMVOC}$ & $\pm 50 \%$ & $\pm 65 \%$ & $\pm 75 \%$ & $\pm 35 \%$ & $\pm 45 \%$ & $\pm 65 \%$ & $\pm 20 \%$ & $\pm 20 \%$ & $\pm 25 \%$ \\
$\mathrm{NO}_{x}$ & $\pm 35 \%$ & $\pm 65 \%$ & $\pm 95 \%$ & $\pm 35 \%$ & $\pm 50 \%$ & $\pm 80 \%$ & $\pm 295 \%$ & $\pm 150 \%$ & $\pm 125 \%$ \\
$\mathrm{SF}_{6}$ & $\pm 35 \%$ & $\pm 35 \%$ & $\pm 35 \%$ & $\pm 20 \%$ & $\pm 20 \%$ & $\pm 25 \%$ & $\pm 15 \%$ & $\pm 20 \%$ & $\pm 20 \%$ \\
$\mathrm{SO}_{2}$ & $\pm 110 \%$ & $\pm 95 \%$ & $\pm 100 \%$ & $\pm 100 \%$ & $\pm 80 \%$ & $\pm 100 \%$ & $\pm 55 \%$ & $\pm 55 \%$ & $\pm 55 \%$ \\
$\mathrm{BC}$ & $\pm 125 \%$ & $\pm 110 \%$ & $\pm 110 \%$ & $\pm 110 \%$ & $\pm 95 \%$ & $\pm 110 \%$ & $\pm 70 \%$ & $\pm 70 \%$ & $\pm 70 \%$ \\
$\mathrm{OC}$ & $\pm 125 \%$ & $\pm 110 \%$ & $\pm 115 \%$ & $\pm 110 \%$ & $\pm 95 \%$ & $\pm 110 \%$ & $\pm 70 \%$ & $\pm 75 \%$ & $\pm 75 \%$ \\
\hline
\end{tabular}

tainties than AGTP values (i.e., uncertainties are correlated). Table 7 illustrates the difference between uncertainties in AGTP, GTP, and GWP values. GTP uncertainties are typically $\pm 10-15$ percentage points below those of AGTP, and since the $\mathrm{AGTP}_{\mathrm{CO}_{2}}$ uncertainties are not strongly dependent on the time horizon, they do not affect the uncertainties over different time horizons for other pollutants' GTP values much. GWP calculations use the same parameters as GTP, and although we do not use GWP in our results, we include the uncertainties in the table for comparison. Overall, we find less uncertainty using GWP than the other metrics (Reisinger et al., 2010), except for $\mathrm{NO}_{x}$. The GWP calculations are not dependent on the highly uncertain climate sensitivity, since it does not relate to global temperature change. Thus, it is expected to have lower uncertainties. $\mathrm{NO}_{x}$ has overlapping indirect effects, with highly uncertain $\mathrm{RF}$ values, which suggest that the GWP20 values can be both negative and positive, with a median close to zero. Thus, it has very high uncertainty.

A few other studies have investigated the uncertainties of AGTP and GTP values, but it is difficult to compare those as there are many different sources of uncertainties from many different models and data sets. Our GTP uncertainty results are generally higher than the Olivié and Peters (2013) estimates since we also include uncertainties in lifetime and $\mathrm{RF}$ values of non- $\mathrm{CO}_{2}$ species. Their GTP50 uncertainties for $\mathrm{BC}(-62$ to $+67 \%), \mathrm{CH}_{4}(-38$ to $+48 \%), \mathrm{N}_{2} \mathrm{O}(-16$ to $+25 \%)$ and $\mathrm{SF}_{6}(-17$ to $+25 \%)$ are higher than their GWP uncertainties, mainly due to the dependence on the uncertain climate response (Olivié and Peters, 2013). Another study (Fuglestvedt et al., 2010) found similar uncertainties for GTP50 values for BC (around 200\%) and smaller values for $\mathrm{CH}_{4}(50 \%)$ compared to our results, and essentially zero for $\mathrm{N}_{2} \mathrm{O}$, when only looking at sensitivity to the cli- mate response. $\mathrm{N}_{2} \mathrm{O}$ is a special case as it has a similar average lifetime to $\mathrm{CO}_{2}$, and thus it has similar climate sensitivity uncertainty as $\mathrm{CO}_{2}$, which can be seen in Fig. 7 for AGTP values. The normalization of GTP therefore cancels out the climate sensitivity effect. Based on an evaluation of several studies (including Reisinger et al., 2010), Myhre et al. (2013b) assessed the uncertainty of $\mathrm{CH}_{4}$ for GTP100 to be $\pm 75 \%$, which is close to our estimate. Furthermore, Joos et al. (2013) found uncertainties for $\mathrm{CO}_{2}$ AGTP values at 50 $( \pm 45 \%)$ and 100 years $( \pm 90 \%)$, based on the spread of multiple climate models. Overall, we find the uncertainties to be consistent with other studies, but highly variable depending on data sets and choices.

\subsection{Uncertainty of all components}

Total uncertainties in production- and consumption-based emission estimates reflect a combination of uncertainties from the economic data (IO data for regions and sectors), emissions data (tons of the pollutants occurring in regions and sectors), and metric parameters (RF and lifetime for the pollutants, and the resulting climate response). Additionally, the emissions of a region in a consumption perspective is a combination of domestic emissions as well as emissions occurring in other regions (due to emissions embodied in trade), which change the mix of pollutants and inherits uncertainties from the regions and sectors they occur in. To facilitate our discussion, we aggregate the 58 economic sectors (post analysis) into 9 sectors. The results are strongly dependent on different perspectives: (1) production and consumption, (2) relative or absolute metric values, (3) the time horizon of the metric, (4) global, regional, or sectoral level, and (5) mix of pollutants included. To illustrate the largest differences, 

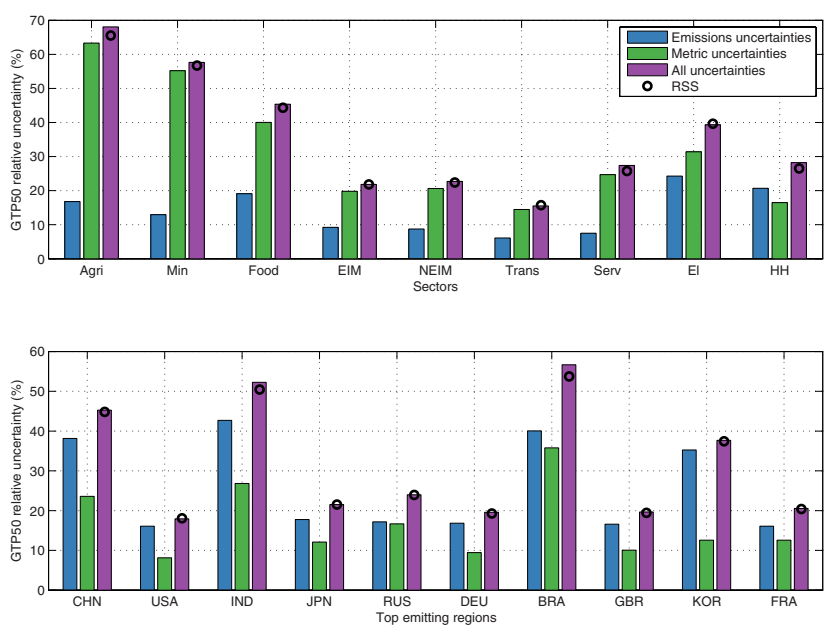

Figure 8. Territorial perspective of emissions and metric uncertainty using GTP50. The top graph shows global emissions in sectors they occur in, while the bottom graph shows regional emissions. Each of the components is represented by an individual MC. The black circle indicates the aggregated RSS uncertainty. The uncertainty represents the 5-95\% CI.

we focus on comparing points 1,2 , and 4 , as 3 has been discussed extensively elsewhere (Myhre et al., '2013b).

In the allocations of metric values in the MRIO model, we choose to use 50-year time horizon, as discussed earlier: it is consistent with other recent studies, and consistent with the $2{ }^{\circ} \mathrm{C}$ policy target. Because of the differences between absolute and relative metric uncertainties, we compare both when including perturbations on all components in the last section.

Figure 8 shows uncertainties from the components with aggregated sectors and the top emitting regions, using GTP50 production emissions. The three different bars represent individual MC ensembles with only the respective components perturbed. At the sector level, the uncertainties in emissions data is generally the smallest (from 6 to $24 \%$ for sectors), except for households where large and highly uncertain emissions of $\mathrm{BC}$ and $\mathrm{OC}$ occur. Uncertainty in metrics has a range from 14 to $63 \%$, especially large in sectors with non$\mathrm{CO}_{2}$ emissions (e.g., agriculture and mining). Pollutants with higher relative uncertainty of emissions compared to uncertainty of metric values at GTP50 (including BC, OC, and $\mathrm{NF}_{3}$ at disaggregated levels) will tend to give higher uncertainty to emissions, while the other pollutants will give higher uncertainty to metrics.

The sector aggregation means that high and low uncertainties from different sector sizes are mixed, and thus single sectors like construction have a higher uncertainty than the aggregated services sector. Disaggregation from the global sector perspective to the national and sector levels reveals that emission uncertainties are a function of aggregations (sectoral uncertainties are adjusted to specific national uncertain-
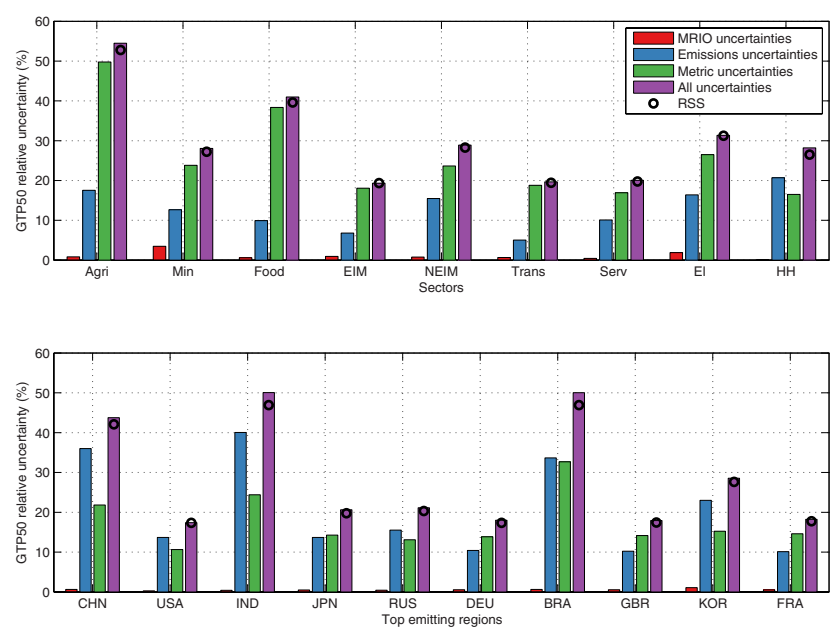

Figure 9. Consumption perspective of emissions, metric and MRIO uncertainty using GTP50. The top graph shows global emissions by sector, while the bottom graph shows regional consumption.

ties), while the metric uncertainties are not directly dependent on sector aggregation and will therefore not scale the same way. Consequently, disaggregated levels generally find much higher emission uncertainties than metric uncertainties. For the top 10 emitters, disaggregated sectoral emission uncertainties have a median value between 13 and 94 percentage points above the national aggregate, while the metric uncertainties have a median value between 4 and 16 percentage points above the national aggregated level.

Furthermore, emission uncertainties are scaled according to sector sizes, whereas metric uncertainties are not. This means that emission uncertainties are a combination of mix of pollutants and mix of sector sizes, while metric uncertainties only reflect the mix of pollutants (where uncertainty is dominated by temperature response). This makes the global sectoral and national level quite different, since the national level represent various sector sizes with uncertainties according to the functional relationship, while the global sectors might only represent large or small sectors. Because of this, emission uncertainties usually dominate at the national level as the regions are less aggregated (each region consists of 58 sectors) than the global sectors (each consisting of 129 regions). The difference in regional uncertainties is attributed to different mix of territorial pollutants being emitted, the sector and economy sizes, and if the regions are developed or developing nations.

Uncertainties from the different components do not linearly contribute to total uncertainty in the end results, and thus we calculate the total uncertainty in two different ways: an MC run with everything perturbed and an RSS approach combining the individual components. While the MC run is considered the more robust method since it takes into account all data points, including the effect of error canceling, the RSS method is an approximation of error propaga- 
tion which assumes no correlation and normal distributions. The two methods agree in most cases, which imply that there are only small correlations between the components and that the global-level data is close to normally distributed. This further implies that a full computationally intensive MC run with all components perturbed might not be necessary in ideal cases as the RSS method can approximately derive the results.

Figure 9 shows uncertainties from the consumption perspective, thus including MRIO uncertainties. In general, the emissions embodied in imports and exports inherit uncertainties from the economic data of the region where the emissions occur. Consumption emissions include territorial emissions and emissions from imports, while they exclude emissions from exports. Since our MRIO uncertainties only include parametric uncertainties, they tend to be small due to the cancellation effect discussed earlier, which is consistent with other similar studies (Lenzen et al., 2010; Wilting, 2012; Bullard and Sebald, 1988; Peters, 2007). Structural uncertainties, including differences in data sources, MRIO models, and definitions of consumption-based emissions, may be a larger source of uncertainty (Andrew and Peters, 2013). The differences in the data sets and methods used to calculate consumption-based $\mathrm{CO}_{2}$ emissions have shown to be relatively small, with roughly $10 \%$ for the USA for 2007 (Peters et al., 2012). Although various studies use different input data and models, Peters et al. (2012) found the results of major emitters to be robust across studies, even though $10 \%$ differences are not uncommon.

The top emitting regions are large economies, and therefore have mostly large economic sectors and therefore low aggregated uncertainties. The consumption perspective also mixes pollutants in regions and sectors since the supply chain is taken into account, leading to dilution of the sectoral and regional variability since multi-sectoral dependence for a single consuming sector is common (e.g., the production of a car needs input from other sectors, especially electricity). Households are considered final demand in the MRIO model, and therefore their emissions are not allocated through the economic model and thus do not inherit economic uncertainties.

Contrary to the production perspective, the national consumption-based emissions are more dominated by metric uncertainties, due to different mix of pollutants. Disaggregation of the consumption emissions reveals that metric uncertainties usually dominate the sectors for the top emitters, and that uncertainties in economic data also usually increase more than the emission uncertainties at the sector level. For these nations, disaggregated sectoral emission uncertainties have a median value between 2 and 11 percentage points above the national aggregate, while the metric uncertainties have a median value between 3 and 9 percentage points above the national aggregated level, and economic uncertainty have an increase between 4 and 10 percentage points.

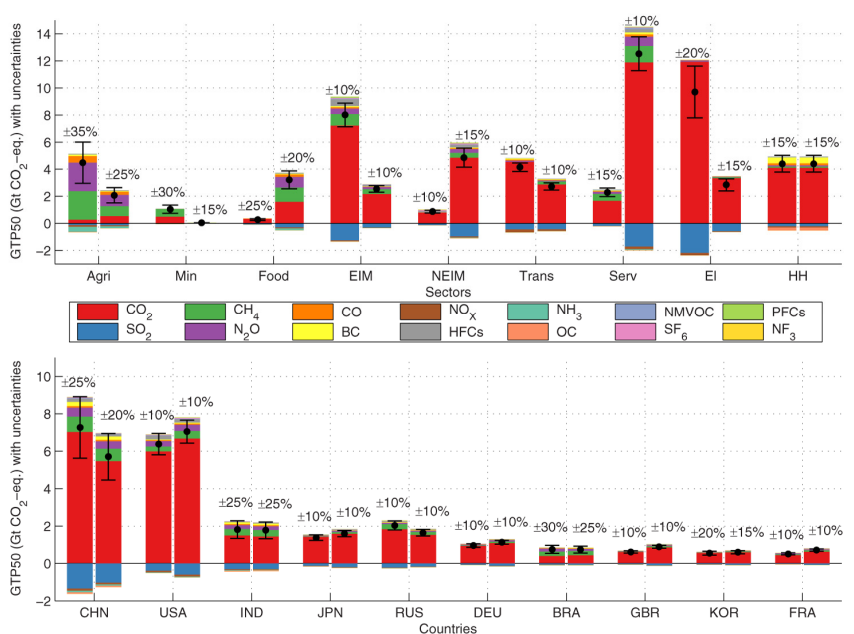

Figure 10. GTP values and uncertainties for territorial (first bars) and consumption (second bars) perspectives. Percentages on top of the bars indicate total uncertainty (rounded to the closest $5 \%$ ).

Figure 10 show GTP values and uncertainties for the same sectors and regions, for both territorial and consumption perspectives. Comparing the allocation differences due to different perspectives help explain the change in uncertainties when going from production to consumption. Agriculture and mining see the largest sectoral decrease in uncertainties due mainly to different mix of pollutants (increased $\mathrm{CO}_{2}$ ), while transport and non-energy intensive manufacturing see an increase due to increased allocations of non- $\mathrm{CO}_{2}$ emissions like $\mathrm{SO}_{2}$. Similar differences can be seen for regions: India and Brazil are uncertain due to $\mathrm{SO}_{2}$ and $\mathrm{CH}_{4}$ emissions, while the US emissions consist mostly of $\mathrm{CO}_{2}$ uncertainty.

Most regions have quite similar uncertainty in both perspectives, indicating that the economic uncertainties do not play a major role for the large regions. The difference of uncertainties in the allocation perspectives can mainly be attributed to (1) different mix of pollutants and (2) different allocations of emissions to sectors. The first effect gives net emission importers higher uncertainty in some sectors, due to highly uncertain pollutants (e.g., the share of non$\mathrm{CO}_{2}$ emissions in the $\mathrm{UK}$ is $30 \%$ higher using consumptionbased emissions, assuming absolute values), while other sectors decrease uncertainties due to the increased allocation of $\mathrm{CO}_{2}$. The second effect is introduced when aggregating sectors to the national level. The production emissions in a region are often dominated by a few large sectors, while the consumption-based emissions are distributed more evenly among the same sectors. This difference in distribution cause different relative errors on the aggregated result, even tough the sectoral uncertainties and the sum of emissions might be the same. Thus, on the national level, this effect creates smaller uncertainties. The combined results may give consumption-based emissions less uncertainty than produc- 


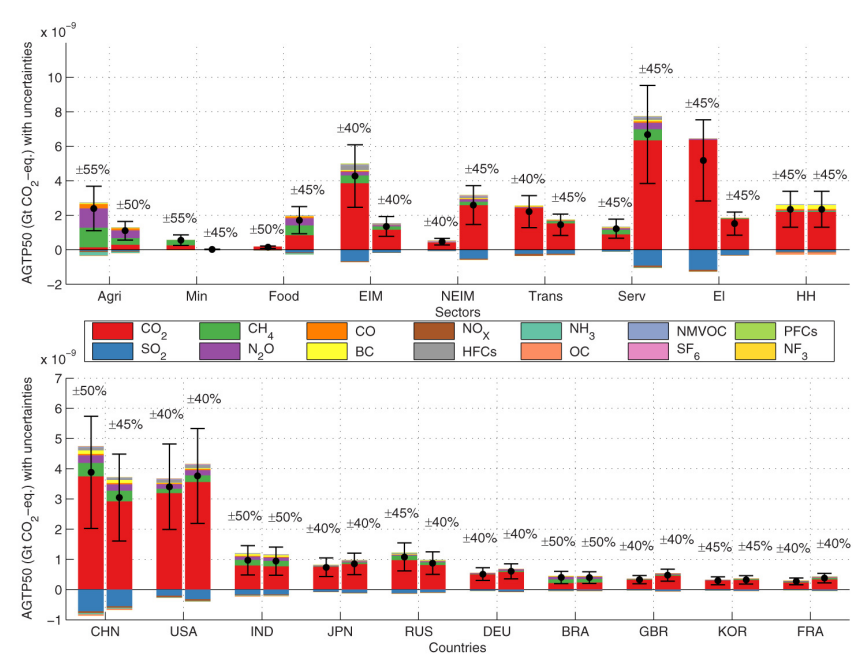

Figure 11. AGTP values and uncertainties for territorial (first bars) and consumption (second bars) perspectives. The uncertainty reflects a combination of all pollutants including $\mathrm{CO}_{2}$. Percentages on top of the bars indicate total uncertainty (rounded to closest $5 \%$ ).

tion emissions on the national level (usually within $1-2 \%$ for the top emitters).

In the Supplement, we demonstrate how to calculate consumption uncertainty analytically for a simple one-sector, two-region world economy. This reveals that the consumption uncertainty can be lower, under conditions that are not unusual. How this analytical solution generalizes to larger systems requires further research. A similar finding was also found by Peters et al. (2012).

The AGTP emissions include uncertainties in $\mathrm{CO}_{2}$, and thus sectoral and regional uncertainties are larger and differences are reduced since it is the most common pollutant (Fig. 11). In this view, e.g., Chinese and US emissions overlap greatly within the given uncertainties, suggesting that the ordering is uncertain. The corresponding GTP values have less overlap. This may have large policy implications in terms of responsibility. Other choices may also change the relative importance and uncertainty of regions and sectors. Choosing 20 years as time horizon would give lower relative uncertainties for all pollutants because of lower uncertainties for lifetime and climate sensitivity, except for $\mathrm{SO}_{2}, \mathrm{BC}$, $\mathrm{OC}$ and $\mathrm{NH}_{3}$ due to their short-lived nature, and thus regions and sectors with large emissions or consumption of SLCFs will be given larger uncertainties. Choosing 100 years will in most cases give higher relative uncertainties and give SLCFs less importance (see Fig. 7). Overall, we find the uncertainties to be highly sensitive to methods and choices.

\section{Discussion}

This study investigates parametric uncertainties in the temperature response to territorial- and consumption-based emissions with uncertainty contributions from economic data, emissions data, and metric parameters. Structural uncertainties (data set and model differences) and other contributing factors such as emission metric, attribution methods, and indicators of climate change may be equally important when assessing uncertainties, but we did not investigate those here (den Elzen et al., 2005; Höhne et al., 2010; Peters et al., 2012; Moran and Wood, 2014). Earlier studies have shown relatively low uncertainties when estimating countries' contributions to climate change. Prather et al. (2009) estimated an uncertainty range of -27 to $+32 \%$ for the global warming caused by Annex I countries for the period 1990-2002 $\left(0.11 \pm 0.03^{\circ} \mathrm{C}\right.$ using $16-84 \%$ confidence interval). Similar to them, we find that climate modeling generally has the largest contribution to total uncertainty on an aggregated level.

Our analysis has shown that uncertainties change depending on the (1) allocation perspective, (2) pollutants included, (3) metric and (4) aggregation. These changes in uncertainties may have implications for future mitigation policies.

First, we found little difference in the uncertainties in production- and consumption-based emissions. It is often assumed that consumption-based emissions are more uncertain (Peters, 2008). Consistent with others, we find that parametric uncertainties are smaller, while structural uncertainties are generally larger (Peters et al., 2012; Moran and Wood, 2014). Lenzen et al. (2010) found lower uncertainties for the UK carbon footprint (relative standard deviation of $5 \%$ in $2001)$ than our results $( \pm 9 \%)$, but this is probably because we include other pollutants and metric uncertainties. In a recent study, Moran and Wood (2014) found that parametric uncertainties in consumption-based emissions were generally lower than the uncertainty in territorial-based emissions and the structural uncertainties (model spread). They found that most major economies' carbon footprint results are within $10 \%$, consistent with our results. However, it is difficult to gauge how robust the parametric consumptionbased emission uncertainties are. On the one hand, our chosen input uncertainties may be underestimated but there exists scant data to verify this. Increasing the uncertainties requires rebalancing the MRIO tables used in the analysis, which may introduce correlations and additional uncertainties resulting from the balancing process. Due to the computationally expensive nature of this type of analysis, further work would be required to assess the implications of rebalancing for each perturbation. On the other hand, the small uncertainties may reflect a realistic canceling of numerous random errors (Lenzen et al., 2010). Settling these issues is a topic of future research.

Second, including SLCFs creates larger differences between regions' and sectors' uncertainties, where, e.g., emissions from Brazil and India are much more uncertain than those of the other top 10 emitters due to large emissions in agriculture. Sectors such as agriculture, electricity, and manufacturing have large non- $\mathrm{CO}_{2}$ emissions, causing larger 
cooling and warming effects and additional uncertainties in the net change. It is often argued that a shorter time horizon (e.g., 20 years) places more emphasis on the short-lived pollutants relative to $\mathrm{CO}_{2}$, while with a longer time horizon (e.g., 100 years) the warming from $\mathrm{CO}_{2}$ dominates. There is also a similar trade off with uncertainty: in the short term, the uncertainties are much larger due to the SLCFs, and thus the temperature effect of policies to reduce SLCFs has a more uncertain outcome; in the long term, the more certain temperature effects of $\mathrm{CO}_{2}$ dominate and the uncertainty due to the SLCFs becomes less relevant. Thus, uncertainty may tend to favor a more certain outcome for $\mathrm{CO}_{2}$ mitigation compared to SLCFs. This hypothesis would require deeper analysis using economic and other models that incorporate uncertainty into decision making.

Third, the GTP values have much smaller uncertainties than the AGTP metric due to (1) the dominance of $\mathrm{CO}_{2}$ which has $\mathrm{GTP}_{\mathrm{CO}_{2}}=1$ and no uncertainty by definition and (2) the scaling by $\mathrm{AGTP}_{\mathrm{CO}_{2}}$ in the denominator which effectively reduces the impact of climate-sensitivity uncertainty in the GTP. This suggests that a normalized metric, GTP, may be better than an absolute metric, AGTP, in terms of reducing uncertainties. In perspective, the underlying uncertainties are ultimately the same, but they have just been shifted to different variables and scaled out. Thus, a GTP focus may give the impression of greater uncertainty in $\mathrm{CO}_{2}$, while the uncertainty is really translated to the GTP of other species. Other metrics, like the GWP, have lower uncertainties then the GTP as they do not include the response of the climate system (Olivié and Peters, 2013). Despite the metric uncertainties, it is unclear what role they should play in policy. From a scientific point of view the uncertainties are important, but in policy, once a metric and its parameters are chosen, their uncertainties are likely to be disregarded in subsequent policy applications. This is an area that needs further consideration.

Fourth, aggregation changes the importance of the uncertainty contribution between the different components (economic data, emissions data, and metric), as only the emissions data uncertainty have been estimated at both sector and regional level, while they all are affected by reduction in uncertainties by aggregation. On the global sectoral level, uncertainties are dominated by metrics. For the regions, emission uncertainties often dominate metric uncertainties. At the sector level, much larger variations are seen, with even economic uncertainties dominating in very small sectors. Thus, the role of uncertainties may differ depending on the level of aggregation.

These results presented are broadly in line with the existing literature on this topic (Wilting, 2012; Fuglestvedt et al., 2010; Joos et al., 2013; Lenzen et al., 2010; Myhre et al., 2013b; Olivié and Peters, 2013). However, our results are limited by the quality of the uncertainty information available as input into our analysis. Despite the widespread usage of the input data in a wide variety of studies, there still exists virtually no uncertainty information on economic data, and limited data on the uncertainties in emission statistics and metric parameters.

A major difficulty of uncertainty analysis is the issue of correlations. There is a large need for addressing correlations in data sets and uncertainties, as these may have significant impacts on the results. We see several places where correlations could be important: (1) correlations in the metric parameters, (2) balancing constraints (e.g., if the production of electricity is low, then the consumption of electricity has to be low), (3) between data sets (e.g., a perturbation in fossil fuel use in the economic data set should be reflected by a similar perturbation in the emissions data set), and (4) in each MC ensemble the perturbation given to a particular region/sector combination may be correlated with other region/sectors (e.g., if Norway's emissions from cement production in one ensemble are low, then Sweden's emissions from the same sector may also be low due to correlations in emissions factors).

In our analysis, we have explored correlations for metric parameters (temperature and $\mathrm{CO}_{2} \mathrm{IRF}$ ), which we found to have a small effect on the results, addressing point 1 . The effect of correlations in the MRIO data, and linkages to emission data through energy consumption, has not previously been quantified, and this remains an important area of research. Although these correlations may change the uncertainty outcome, implementation of correlations in emissions and economic data faces considerable computational and conceptual hurdles. First, due to the large data sets used in this analysis, the correlation matrix would be prohibitively large (approximately 1015 elements), posing serious computational issues. Second, there are little or no data indicating correlations in uncertainties in sectoral economic data or emissions data, and populating a correlation matrix of the necessary size would therefore be largely guesswork. Given these constraints, we suggest that the best way forward is to generate small test cases to assess the importance of correlations in small data sets, but we leave this for future work.

\section{Conclusions}

We analyzed emissions from 129 countries and 58 sectors with 31 SLCFs and GHGs, estimating countries' territorial and consumption-based emissions for 2007. We use topdown uncertainty estimates to derive sector-level uncertainties, and use these to perturb the economic data, emissions data, and metric parameters in a Monte Carlo model. We find the results are sensitive to some parameters (such as the uncertainty of the climate response and the data sets) and assumptions (such as developing countries are assigned twice the uncertainty for emissions and economic data), but especially to choices regarding allocation perspective, pollutants included, metric used, and aggregation level of the results.

We find only minor uncertainty differences between allocation perspectives (production versus consumption) for the 
top regions, and uncertainties in the economic data are very small for the large countries. Since economic data generally do not have uncertainty information, it was necessary to estimate the uncertainties of the economic data and there is little data to verify our estimates. At the sectoral level, larger differences between production and consumption are found. The inclusion of SLCFs increases both the emissions and metric uncertainties, and gives larger variations between regions and sectors. A different choice of time horizon would change the prioritization of the gases and corresponding uncertainties. At the global level, the metric uncertainty (which is dominated by climate sensitivity) dominates emission and economic uncertainty. At the regional level, the uncertainties from emissions are more important.

Our work points to key areas of future research required to reduce uncertainties. The climate sensitivity generally dominates uncertainties, and this is where the largest improvements can potentially be made. Most climate sensitivity literature focuses on the long-term sensitivity, whereas for metrics (and undoubtedly most mitigation analysis), the temporal path to the equilibrium response is most relevant (impulse response function). Thus, we suggest much deeper analysis is needed on the time evolution of the temperature response. Emission statistics are routinely collected but generally have poorly defined uncertainties. Our work indicates that large improvements in the reporting and analysis of emission uncertainties are needed. Additional metric uncertainties can be improved through a better characterization of metric parameters (radiative efficiencies and lifetimes). Reducing uncertainties in metrics and emission statistics will reduce both uncertainties in production- and consumption-based emissions. The uncertainty in the economic data was necessarily based on crude assumptions. While we found that the economic uncertainties were small, this result requires confirmation by more comprehensive analyses, including, critically, uncertainty correlations, which were excluded from our analysis. Reducing uncertainties in the economic data will have the effect of reducing uncertainties in consumption-based emissions only.

Acknowledgements. The authors acknowledge funding from the Norwegian Research Council project "Quantifying the global socio-economic and policy drivers for Brazil's contribution to global warming" (project no. 196090).

Edited by: D. Kirk-Davidoff

\section{References}

Aamaas, B., Peters, G. P., and Fuglestvedt, J. S.: Simple emission metrics for climate impacts, Earth Syst. Dynam., 4, 145-170, doi:10.5194/esd-4-145-2013, 2013.

Andres, R. J., Boden, T. A., Bréon, F.-M., Ciais, P., Davis, S., Erickson, D., Gregg, J. S., Jacobson, A., Marland, G., Miller, J., Oda,
T., Olivier, J. G. J., Raupach, M. R., Rayner, P., and Treanton, K.: A synthesis of carbon dioxide emissions from fossil-fuel combustion, Biogeosciences, 9, 1845-1871, doi:10.5194/bg-9-18452012, 2012.

Andrew, R. M. and Peters, G. P.: A multi-region input-output table based on the global trade analysis project database (GTAPMRIO), Eco. Syst. Res., 25, 99-121, 2013.

Andrew, R. M., Davis, S. J., and Peters, G. P.: Climate policy and dependence on traded carbon, Environ. Res. Lett., 8, 034011, doi:10.1088/1748-9326/8/3/034011, 2013.

Bond, T. C., Streets, D. G., Yarber, K. F., Nelson, S. M., Woo, J. H., and Klimont, Z.: A technology-based global inventory of black and organic carbon emissions from combustion, J. Geophys. Res.-Atmos. (1984-2012), 109, D14203, doi:10.1029/2003JD003697 2004.

Boucher, O., Randall, D., Artaxo, P., Bretherton, C., Feingold, G., Forster, P., Kerminen, V., Kondo, Y., Liao, H., Lohmann, U., P. Rasch, S. K. Satheesh, S. Sherwood, Stevens, B., and Zhang, X. Y.: Clouds and aerosols, in: Climate Change 2013: The Physical Science Basis. Contribution of Working Group I to the Fifth Assessment Report of the Intergovernmental Panel on Climate Change, edited by: Stocker, T. F., Qin, D., Plattner, G.-K., Tignor M., Allen, S. K., Boschung, J., Nauels, A., Xia Y., Bex, V., and Midgley, P. M.: Cambridge University Press, Cambridge, United Kingdom and New York, NY, USA, 2013.

Bullard, C. W. and Sebald, A. V.: Monte Carlo Sensitivity Analysis of Input-Output Models, The Review of Economics and Statistics, 70, 708-712, 1988.

Clarisse, L., Clerbaux, C., Dentener, F., Hurtmans, D., and Coheur, P.-F.: Global ammonia distribution derived from infrared satellite observations, Nat. Geosci., 2, 479-483, 2009.

Collins, W., Derwent, R., Johnson, C., and Stevenson, D.: The oxidation of organic compounds in the troposphere and their global warming potentials, Clim. Change, 52, 453-479, 2002.

Davis, S. J. and Caldeira, K.: Consumption-based accounting of $\mathrm{CO}_{2}$ emissions, Proc. Natl. Acad. Sci., 107, 5687-5692, 2010.

den Elzen, M., Fuglestvedt, J. S., Höhne, N., Trudinger, C., Lowe, J., Matthews, B., Romstad, B., Pires de Campos, C., and Andronova, N.: Analysing a countries' contribution to climate change: scientific and policy-related choices, Environ. Sci. Pol., 8, 614-636, 2005.

Derwent, R., Collins, W., Johnson, C., and Stevenson, D.: Transient behaviour of tropospheric ozone precursors in a global 3-D CTM and their indirect greenhouse effects, Clim. Change, 49, 463487, 2001.

Elliott, J., Franklin, M., Foster, I., Munson, T., and Loudermilk, M.: Propagation of Data Error and Parametric Sensitivity in Computable General Equilibrium Models, Comput. Econ., 39, 219241, doi:10.1007/s10614-010-9248-5, 2012.

European Commission: Emission Database for Global Atmospheric Research (EDGAR), release version 4.2, available at: http:// edgar.jrc.ec.europa.eu (last access: 24 February 2014), 2011.

Fuglestvedt, J. S., Shine, K. P., Berntsen, T., Cook, J., Lee, D. S., Stenke, A., Skeie, R. B., Velders, G. J. M., and Waitz, I. A.: Transport impacts on atmosphere and climate: Metrics, Atmos. Environ., 44, 4648-4677, doi:10.1016/j.atmosenv.2009.04.044, 2010. 
Granger Morgan, M., Henrion, M., and Small, M.: Uncertainty: a guide to dealing with uncertainty in quantitative risk and policy analysis, Cambridge University Press Cambridge, 1990.

Hertwich, E. G. and Peters, G. P.: Carbon footprint of nations: A global, trade-linked analysis, Environ. Sci. Technol., 43, 64146420, 2009.

Hoekstra, A. Y. and Mekonnen, M. M.: The water footprint of humanity, P. Natl. Acad. Sci. USA, 109, 3232-3237, doi:10.1073/pnas.1109936109, 2012.

Höhne, N., Blum, H., Fuglestvedt, J., Skeie, R. B., Kurosawa, A., Hu, G., Lowe, J., Gohar, L., Matthews, B., de Salles, A. C., and Ellermann, C.: Contributions of individual countries' emissions to climate change and their uncertainty, Clim. Change, 106, 359391, doi:10.1007/s10584-010-9930-6, 2010.

Inomata, S. and Owen, A.: COMPARATIVE EVALUATION OF MRIO DATABASES, Eco. Syst. Res., 26, 239-244, doi:10.1080/09535314.2014.940856, 2014.

IPCC: Climate change 2007: Contribution of Working Group I to the Fourth Assessment Report of the Intergovernmental Panel on Climate Change, Cambridge University Press, Cambridge, United Kingdom and New York, NY, USA, 2007.

IPCC: Summary for Policymakers, in: Climate Change 2013: The Physical Science Basis. Contribution of Working Group I to the Fifth Assessment Report of the Intergovernmental Panel on Climate Change, edited by: Stocker, T. F., Qin, D., Plattner, G.-K., Tignor, M., Allen, S. K., Boschung, J., Nauels, A., Xia, Y., Bex, V., and Midgley, P. M., Cambridge University Press, Cambridge, United Kingdom and New York, NY, USA, 2013.

IPCC: Chapter 5: Drivers, Trends and Mitigation, in: Climate Change 2014: Mitigation of Climate Change. Contribution of Working Group III to the Fifth Assessment Report of the Intergovernmental Panel on Climate Change, edited by: Edenhofer, O., Pichs-Madruga, R., Sokona, Y., Farahani, E., Kadner, S., Seyboth, K., Adler, A., Baum, I., Brunner, S., Eickemeier, P., Kriemann, B., Savolainen, J., Schlömer, S., von Stechow, C., Zwickel, T., and Minx, J. C.: Cambridge University Press, Cambridge, United Kingdom and New York, NY, USA., 17-18 and 61-62, 2014.

Jackson, J., Choudrie, S., Thistlethwaite, G., Passant, N., Murrells, T., Watterson, J., Mobbs, D., Cardenas, L., Thomson, A., Leech, A., Li, Y., Manning, A., Walker, C., Brophy, N., Sneddon, S., Pierce, M., Thomas, J., and Brown, K.: UK Greenhouse Gas Inventory 1990 to 2007 - ANNEX 8, Uncertainties 0955482380 , 2009.

Joos, F., Roth, R., Fuglestvedt, J. S., Peters, G. P., Enting, I. G., von Bloh, W., Brovkin, V., Burke, E. J., Eby, M., Edwards, N. R., Friedrich, T., Frölicher, T. L., Halloran, P. R., Holden, P. B., Jones, C., Kleinen, T., Mackenzie, F. T., Matsumoto, K., Meinshausen, M., Plattner, G.-K., Reisinger, A., Segschneider, J., Shaffer, G., Steinacher, M., Strassmann, K., Tanaka, K., Timmermann, A., and Weaver, A. J.: Carbon dioxide and climate impulse response functions for the computation of greenhouse gas metrics: a multi-model analysis, Atmos. Chem. Phys., 13, 27932825, doi:10.5194/acp-13-2793-2013, 2013.

Joshi, M., Hawkins, E., Sutton, R., Lowe, J., and Frame, D.: Projections of when temperature change will exceed $2{ }^{\circ} \mathrm{C}$ above preindustrial levels, Nat. Clim. Change, 1, 407-412, 2011.

Kanemoto, K., Moran, D., Lenzen, M., and Geschke, A.: International trade undermines national emission reduction targets: New evidence from air pollution, Global Environ. Change, 24, 52-59, doi:10.1016/j.gloenvcha.2013.09.008, 2013.

Karstensen, J., Peters, G. P., and Andrew, R. M.: Attribution of $\mathrm{CO}_{2}$ emissions from Brazilian deforestation to consumers between 1990 and 2010, Environ. Res. Lett., 8, 024005, doi:10.1088/1748-9326/8/2/024005, 2013.

Kirschke, S., Bousquet, P., Ciais, P., Saunois, M., Canadell, J. G., Dlugokencky, E. J., Bergamaschi, P., Bergmann, D., Blake, D. R., and Bruhwiler, L.: Three decades of global methane sources and sinks, Nat. Geosci., 6, 813-823, 2013.

Ko, M., Newman, P., Reimann, S., and Strahan, S.: Lifetimes of stratospheric ozone-depleting substances, their replacements, and related species, SPARC Report, 2013.

Lenzen, M.: Errors in Conventional and Input - Output - based Life - Cycle Inventories, J. Industrial Ecol., 4, 127-148, 2000.

Lenzen, M., Wood, R., and Wiedmann, T.: Uncertainty analysis for multi-region input-output models-a case study of the UK's carbon footprint, Eco. Syst. Res., 22, 43-63, 2010.

Lenzen, M., Kanemoto, K., Moran, D., and Geschke, A.: Mapping the Structure of the World Economy, Environ. Sci. Technol., 46, 8374-8381, doi:10.1021/es300171x, 2012a.

Lenzen, M., Moran, D., Kanemoto, K., Foran, B., Lobefaro, L., and Geschke, A.: International trade drives biodiversity threats in developing nations, Nature, 486, 109-112, 2012b.

Lenzen, M., Moran, D., Kanemoto, K., and Geschke, A.: BUILDING EORA: A GLOBAL MULTI-REGION INPUTOUTPUT DATABASE AT HIGH COUNTRY AND SECTOR RESOLUTION, Eco. Syst. Res., 25, 20-49, doi:10.1080/09535314.2013.769938, 2013.

Leontief, W.: Environmental Repercussions and the Economic Structure: An Input-Output Approach, The Rev. Eco. Stat., 52, 262-271, 1970.

Levin, I., Naegler, T., Heinz, R., Osusko, D., Cuevas, E., Engel, A., Ilmberger, J., Langenfelds, R. L., Neininger, B., Rohden, C. v., Steele, L. P., Weller, R., Worthy, D. E., and Zimov, S. A.: The global SF6 source inferred from long-term high precision atmospheric measurements and its comparison with emission inventories, Atmos. Chem. Phys., 10, 2655-2662, doi:10.5194/acp-102655-2010, 2010.

Macknick, J.: Energy and $\mathrm{CO}_{2}$ emission data uncertainties, Carbon Managee., 2, 189-205, doi:10.4155/cmt.11.10, 2011.

Marland, G., Hamal, K., and Jonas, M.: How Uncertain Are Estimates of $\mathrm{CO}_{2}$ Emissions?, J. Industrial Ecol., 13, 4-7, doi:10.1111/j.1530-9290.2009.00108.x, 2009.

McDougall, R. A.: Chapter 19: Updating and Adjusting the Regional Input-Output Tables, in: Global Trade, Assistance, and Production: The GTAP 6 Data Base, edited by: Dimaranan, B. V., Center for Global Trade Analysis, Purdue University, 2006.

Miller, R. and Blair, P. D.: Input-output analysis: Foundations and extensions, Englewood Cliffs, NJ, Prentice-Hall, 1985.

Minka, T.: The Lightspeed Matlab toolbox, available at: http://research.microsoft.com/en-us/um/people/minka/software/ lightspeed/ (last access: 18 February 2015), 2014.

Moran, D., and Wood, R.: CONVERGENCE BETWEEN THE EORA, WIOD, EXIOBASE, AND OPENEU'S CONSUMPTION-BASED CARBON ACCOUNTS, Eco. Syst. Res., 26, 245-261, doi:10.1080/09535314.2014.935298, 2014. 
Myhre, G., D. Shindell, F.-M. Bréon, W. Collins, J. Fuglestvedt, J. Huang, D. Koch, J.-F. Lamarque, D. Lee, B. M., T. Nakajima, A. Robock, G. Stephens, Takemura, T., and Zhang, H.: Anthropogenic and Natural Radiative Forcing Supplementary Material, in: Climate Change 2013: The Physical Science Basis. Contribution of Working Group I to the Fifth Assessment Report of the Intergovernmental Panel on Climate Change, edited by: Stocker, T. F., Qin, D., Plattner, G.-K., Tignor, M., Allen, S. K., Boschung, J., Nauels, A., Xia, Y., Bex, V., and Midgley, P. M., available at: www.climatechange2013.org and www.ipcc.ch (last access: 26 February 2015), 2013a.

Myhre, G., Shindell, D., Bréon, F.-M., Collins, W., Fuglestvedt, J., Huang, J., Koch, D., Lamarque, J.-F., Lee, D., Mendoza, B., Nakajima, T., Robock, A., Stephens, G., Takemura, T., and Zhang, H.: Anthropogenic and Natural Radiative Forcing, in: Climate Change 2013: The Physical Science Basis. Contribution of Working Group I to the Fifth Assessment Report of the Intergovernmental Panel on Climate Change, edited by: Stocker, T. F., Qin, D., Plattner, G.-K., Tignor, M., Allen, S. K., Boschung, J., Nauels, A., Xia, Y., Bex, V., and Midgley, P. M., Cambridge University Press, Cambridge, United Kingdom and New York, NY, USA, 2013b.

Narayanan, B., Aguiar, A., and McDougall, R.: Global Trade, Assistance, and Production: The GTAP 8 Data Base, available at: https://www.gtap.agecon.purdue.edu/databases/v8/v8_ doco.asp (last access: 21 March 2012), 2012.

Olivié, D. J. L. and Peters, G. P.: Variation in emission metrics due to variation in $\mathrm{CO}_{2}$ and temperature impulse response functions, Earth Syst. Dynam., 4, 267-286, doi:10.5194/esd-4-267-2013, 2013.

Peters, G.: Personal communication with Robert McDougall: Zero Values, available at: https://www.gtap.agecon.purdue.edu/ network/forum/mailing_list.asp (last access: 15 July 2014), 2006.

Peters, G. P.: Efficient Algorithms for Life Cycle Assessment, Input-Output Analysis, and Monte-Carlo Analysis, Int. J. Life Cy. Assess., 12, 373-380, 2007.

Peters, G. P.: From Production-Based to Consumption-Based National Emission Inventories, Ecol. Eco., 65, 13-23, 2008.

Peters, G. P. and Andrew, R.: A multi-region input-output table based on the global trade analysis project database, Frontier of International Input-Output Analyses, Tokyo, Japan, 2012.

Peters, G. P. and Hertwich, E. G.: $\mathrm{CO}_{2}$ Embodied in International Trade with Implications for Global Climate Policy, Environ. Sci. Technol., 42, 1401-1407, 2008.

Peters, G. P., Aamaas, B., Berntsen, T., and Fuglestvedt, J. S.: The integrated global temperature change potential (iGTP) and relationships between emission metrics, Environm. Res. Lett., 6, 044021, doi:10.1088/1748-9326/6/4/044021, 2011a.

Peters, G. P., Andrew, R., and Lennox, J.: Constructing an Environmentally-Extended Multi-Regional Input-Output Table Using the Gtap Database, Eco. Syst. Res., 23, 131-152, doi:10.1080/09535314.2011.563234, 2011b.

Peters, G. P., Minx, J. C., Weber, C. L., and Edenhofer, O.: Growth in emission transfers via international trade from 1990 to 2008, P. Natl. Acad. Sci., 108, 8903-8908, 2011c.

Peters, G. P., Davis, S. J., and Andrew, R.: A synthesis of carbon in international trade, Biogeosciences, 9, 3247-3276, doi:10.5194/bg-9-3247-2012, 2012.
Peters, G. P., Andrew, R. M., Boden, T., Canadell, J. G., Ciais, P., Le Quere, C., Marland, G., Raupach, M. R., and Wilson, C.: The challenge to keep global warming below $2{ }^{\circ} \mathrm{C}$, Nat. Clim. Change, 3, 4-6, 2013.

Pierrehumbert, R. T.: Short-Lived Climate Pollution, Annu. Rev. Earth Planet. Sci., 42, 341-379, doi:10.1146/annurev-earth060313-054843, 2014.

Prather, M. J., Penner, J., Fuglestvedt, J. S., Raper, S., de Campos, C. P., Jain, A., van Aardenne, J., Lal, M., Wagner, F., Kurosawa, A., Skeie, R. B., Lowe, J., Stott, P., and Höhne, N.: Tracking uncertainties in the causal chain from human activities to climate, Geophys. Res. Lett., 36, L05707, doi:10.1029/2008GL036474, 2009.

Prather, M. J., Holmes, C. D., and Hsu, J.: Reactive greenhouse gas scenarios: Systematic exploration of uncertainties and the role of atmospheric chemistry, Geophys. Res. Lett., 39, L09803, 10.1029/2012GL051440, 2012.

Reisinger, A., Meinshausen, M., Manning, M., and Bodeker, G.: Uncertainties of global warming metrics: $\mathrm{CO}_{2}$ and $\mathrm{CH}_{4}$, Geophys. Res. Lett., 37, L14707, doi:10.1029/2010GL043803, 2010.

Shindell, D. T., Faluvegi, G., Koch, D. M., Schmidt, G. A., Unger, N., and Bauer, S. E.: Improved attribution of climate forcing to emissions, Science, 326, 716-718, 2009.

Shindell, D., Kuylenstierna, J. C. I., Vignati, E., van Dingenen, R., Amann, M., Klimont, Z., Anenberg, S. C., Muller, N., Janssens-Maenhout, G., Raes, F., Schwartz, J., Faluvegi, G., Pozzoli, L., Kupiainen, K., Höglund-Isaksson, L., Emberson, L., Streets, D., Ramanathan, V., Hicks, K., Oanh, N. T. K., Milly, G., Williams, M., Demkine, V., and Fowler, D.: Simultaneously Mitigating Near-Term Climate Change and Improving Human Health and Food Security, Science, 335, 183-189, doi:10.1126/science.1210026, 2012.

Shine, K. P.: The global warming potential - the need for an interdisciplinary retrail, Clim. Change, 96, 467-472, 2009.

Shine, K. P., Fuglestvedt, J. S., Hailemariam, K., and Stuber, N.: Alternatives to the global warming potential for comparing climate impacts of emissions of greenhouse gases, Clim. Change, 68, 281-302, 2005.

Shine, K. P., Berntsen, T. K., Fuglestvedt, J. S., Skeie, R. B., and Stuber, N.: Comparing the climate effect of emissions of shortand long-lived climate agents, Philos. Trans Series A, 365, 19031914, doi:10.1098/rsta.2007.2050, 2007.

Skeie, R. B., Berntsen, T., Aldrin, M., Holden, M., and Myhre, G.: A lower and more constrained estimate of climate sensitivity using updated observations and detailed radiative forcing time series, Earth Syst. Dynam., 5, 139-175, doi:10.5194/esd-5-139-2014, 2014.

Smith, S. J., van Aardenne, J., Klimont, Z., Andres, R. J., Volke, A., and Delgado Arias, S.: Anthropogenic sulfur dioxide emissions: 1850-2005, Atmos. Chem. Phys., 11, 1101-1116, doi:10.5194/acp-11-1101-2011, 2011.

UNEP: The Emissions Gap Report 2012 - Appendix 1, Nairobi, 2012.

van der Werf, G. R., Morton, D. C., DeFries, R. S., Olivier, J. G. J., Kasibhatla, P. S., Jackson, R. B., Collatz, G. J., and Randerson, J. T.: $\mathrm{CO}_{2}$ emissions from forest loss, Nat. Geosci., 2, 737-738, 2009.

Weber, C. L.: Uncertainties in constructing environmental multiregional input-output models, International input-output meeting 
on managing the environment, 9-11 July 2008, Seville, Spain, 1-31, 2008.

Weinzettel, J., Hertwich, E. G., Peters, G. P., Steen-Olsen, K., and Galli, A.: Affluence drives the global displacement of land use, Global Environ, Change, 23, 433-438, doi:10.1016/j.gloenvcha.2012.12.010, 2013.

Weiss, R. F., Mühle, J., Salameh, P. K., and Harth, C. M.: Nitrogen trifluoride in the global atmosphere, Geophys. Res. Lett., 35, L20821, doi:10.1029/2008gl035913, 2008.

Wiebe, K. S., Bruckner, M., Giljum, S., and Lutz, C.: Calculating Energy-Related Co2emissions Embodied in International Trade Using a Global Input-Output Model, Eco. Syst. Res., 24, 113139, doi:10.1080/09535314.2011.643293, 2012.

Wiedmann, T.: A review of recent multi-region input-output models used for consumption-based emission and resource accounting, Ecol. Eco., 69, 211-222, doi:10.1016/j.ecolecon.2009.08.026, 2009. doi:10.1080/09535314.2011.643293, 2012.
Wiedmann, T., Lenzen, M., and Wood, R.: Uncertainty Analysis of the UK-MRIO Model-Results from a Monte-Carlo Analysis of the UK Multi-Region Input-Output Model (Embedded Carbon Dioxide Emissions Indicator), Report to the UK Department for Environment, Food and Rural Affairs by Stockholm Environment Institute at the University of York and Centre for Integrated Sustainability Analysis at the University of Sydney, Defra, London, Project Ref.: EV02033, 2008.

Wild, O., Prather, M. J., and Akimoto, H.: Indirect long - global radiative cooling from $\mathrm{NO}_{x}$ Emissions, Geophys. Res. Lett., 28, 1719-1722, 2001.

Wilting, H. C.: Sensitivity and Uncertainty Analysis in Mrio Modelling; Some Empirical Results with Regard to the Dutch Carbon Footprint, Eco. Syst. Res., 24, 141-171, doi:10.1080/09535314.2011.628302, 2012. 